\title{
Numerical study on breaking solitary wave force on box-girder bridge
}

\author{
Wanli Yang ${ }^{1,2}$, Sijing Li $i^{3}$, Junling Liu' ${ }^{1}$, Wenbo Wu${ }^{1}$, Hui Li ${ }^{1}$ and Ning Wang ${ }^{4^{*}}$
}

\section{${ }^{*}$ Correspondence:}

ning-wang@swjtu.cn

${ }^{4}$ School of Civil Engineering,

Southwest Jiaotong

University, Chengdu 610031,

China

Full list of author information is available at the end of the article

\begin{abstract}
Solitary wave is often used to simulate tsunami propagating in deep water and breaking solitary wave is often used to simulate tsunami bore propagating in shallow water or on land. The breaking solitary wave force on box-girder, which has been widely used in bridge engineering in coastal areas of China, receives few attentions. This study aims to investigate characteristics and generation mechanism of breaking solitary wave force on box-girder numerically. A numerical wave flume with a 1:20 slope was built firstly, then the solitary wave generation ability, wave deformation and wave breaking on the slope, as well as wave force calculation precision, are validated. The water depth $0.6 \mathrm{~m}$, the slope gradient 1:20 and the distance between slope top and box-girder $2.0 \mathrm{~m}$ remain unchanged, while the wave height and clearance changes in different cases. The time histories of horizontal force and vertical force on box-girder can be divided into three and four stages respectively according to their characteristics. The surface of box-girder is decomposed into a series of panels to facilitate exploring tsunami bore force generation mechanism. Results show horizontal force is dominated by static pressure on upstream vertical panels and vertical force is mainly contributed by static pressure on upstream horizontal panels and on panels in the chambers. Tsunami bore overtopping the box-girder deck impacts the top panel vigorously and results in the peak value of negative vertical force.
\end{abstract}

Keywords: Solitary wave, Wave breaking, Tsunami, Coastal bridge, Generation mechanism, Entrapped air, Wave force

\section{Introduction}

Tsunami, one of natural disasters, has caused devastating damage to coastal infrastructure including ports, bridges, houses, etc. In 1960, the Chilean Sea Tsunami caused the death and missing of more than 10,000 people, according to Feng 2005. In 2011, TohokuOki Earthquake (Mw9.0) in Japan caused a massive tsunami and it triggered a nuclear leakage accident at the Fukushima Nuclear Power Plant (Zhu et al. 2006). Tsunami caused serious damages to coastal bridges (Unjoh and Endoh 2006; Kasano et al. 2012; Salem et al. 2014), which are important transportation bonds in coastal areas. Therefore it is of great significance and engineering value to study the tsunami force on coastal bridges. author(s) and the source, provide a link to the Creative Commons licence, and indicate if changes were made. The images or other third party material in this article are included in the article's Creative Commons licence, unless indicated otherwise in a credit line to the material. If material is not included in the article's Creative Commons licence and your intended use is not permitted by statutory regulation or exceeds the permitted use, you will need to obtain permission directly from the copyright holder. To view a copy of this licence, visit http:// creativecommons.org/licenses/by/4.0/. 
Solitary wave is ordinarily used to simulate Tsunami wave propagates in ocean. The solitary wave deforms and breaks up due to the shallow water effect when it propagates to the coast, then it transforms into bores and impacts on the coastal structures. The wave forces on bridge superstructures caused by solitary waves has been widely studied. Seiffert et al. (2014) studied horizontal and vertical forces acting on a twodimensional horizontal plate due to solitary waves experimentally, and results show the vertical uplift forces become larger when the wave amplitude increases and the plate moves closer to the still-water surface. Hayatdavoodi et al. (2014) used physical experiments and CFD software OpenFOAM to study the forces of solitary waves on T-girder bridge, and results show that the forces calculated by OpenFOAM are in good agreement with the laboratory measurements in most cases. Huang et al. (2019) investigated wave forces on the deck with a box girder subjected to solitary wave, the wave force influencing parameters such as wave height, and submergence coefficient were discussed. Zhu and Dong (2020) studied influence of wave height, water depth, submerged depth, etc., on wave force on a T-girder bridge model, results show that wave force is lineally proportional to wave height, and the 3D model can obtain more accurate wave forces than 2D model. Huang et al. (2020) proposed an analytical method for estimating the wave forces on the box-girder superstructure of coastal bridges based on the potential flow theory, and the results show that the girder type has a significant effect on the wave forces of the submerged superstructure.

The record by Kosa et al. (2014) shows that when the East Japan Tsunami occurred in 2011, the broken bore with bore front height $2 \mathrm{~m}$ impacted the costal bridge. However, the un-broken solitary wave, which has different flow field from the broken bore, was employed to study the tsunami force in the above articles. Broken bore should be used when studying tsunami force on coastal bridges. At present, there are two methods to generate the tsunami bore in laboratory or in CFD simulation: (1) dam-break method. This method simulates the tsunami bore by opening the gate of dam quickly to generate dam-breaking bore. The dam-break method, which is convenient and can simulate tsunami bore considerably well, has been used by Sugimoto and Unjoh 2007, Yang et al. 2020, etc. (2) solitary wave breaking method. This method generates a solitary wave at the far end of flume by wave maker, the solitary wave deforms and then breaks to generate tsunami bore when it propagates on the slope placed at the bottom of the flume (the slope simulates continental shelf). This method can reproduce the propagation and evolution process of solitary wave relatively completely, which has been employed by Seiffert et al. 2014, Hayatdavoodi et al. 2014, Huang et al. 2019, Zhu and Dong 2020.

Cross (1967) simulated the tsunami bore propagation in water tank with dry downstream bed by the dam-break method, and studied the impact force on the vertical wall. Sugimoto and Unjoh (2007) measured tsunami force on a reinforced concrete deckgirder bridge and a steel bridge by dam-break method, and compared the damages of the original bridge struck by real tsunami bore and the model bridge struck by dambreak bore in the laboratory. The generation mechanism and characteristics of the peak value of vertical component of the tsunami bore force on girder bridge are investigated by using dam-break method by Yang et al. (2020), the results show the entrapped air in chambers plays an important role for the generation of the vertical force peak value. 
Although the dam-break method is more convenient than the solitary wave breaking method, it cannot simulate the deformation and breaking up of the solitary wave on the continental shelf, which may make the flow field to be different from that of the tsunami bore and ultimately makes the tsunami force generated by the dambreak method quite different from that generated by real tsunami bore. Therefore, even if the solitary wave breaking method is relatively difficult and costly, it has been employed by some scholars to study the tsunami force on coastal bridge. Ramsden and Raichlen (1990) studied the tsunami bore forces on a vertical wall, in which the tsunami bore was generated by solitary wave breaking up on the slope. The results show the maximum runup of the tsunami bore on the wall exceeds twice of the velocity head, and the maximum tsunami bore force occurred after the maximum runup. The calculation formula proposed by Cross (1967) was also verified by Ramsden and Raichlen (1990). Iemura et al. (2007) studied breaking up of the solitary wave on the slope of 1:10 experimentally, and the tsunami bore impacting on T-girder bridge was also investigated. Results show the largest tsunami bore force happens at the largest velocity or at the beginning of the attack. Lau et al. (2011) studied the tsunami bore force on T-girder bridge impacted by broken solitary wave experimentally, the results show that the vertical force was composed of the vertical upward impact peak and the relatively gentle downward lift force after the beam was submerged. Also tsunami forces on bridge deck are proposed to be categorized into four components, i.e. impulsive, slowly-varying, uplift and additional gravity forces. Note that in the experiments by Lau et al. (2011), the solitary wave was generated by releasing water from an elevated water tank over water flume abruptly, it is difficult to control the wave height and wave shape. Park et al. (2018) studied the impact of breaking waves on the coastal cubic structure numerically, the results show that the tsunami force is less sensitive to the mesh size, but is remarkably influenced by the simulation accuracy of shoaling and breaking processes of waves.

At present, the tsunami forces on T-girder and deck-girder bridges have been widely concerned, but the tsunami forces on box-girder bridges, which have been massively built in coastal area of China, have not been involved. This study aims to numerically simulate the propagation and breaking up of solitary wave on the slope with $1 / 20$ gradient, and investigate the characteristics and generation mechanism of breaking solitary wave (also named as tsunami bore) forces on box-girder.

\section{Numerical model and validation}

The widely used commercial software ANSYS Fluent, which is based on finite volume method, is used to solve the Reynolds Averaged Navier-Stokes (RANS) equations in this study. The computational domain consists of water and air, and VOF method is employed to trace the water surface. The solitary wave is calculated by the secondorder solitary wave theory and by the solitary wave generation method proposed by Goring and Raichlen (1980), i.e. the wave is generated by moving the wave paddle. The UDF (User Defined Function) in ANSYS Fluent is used to control the position of the wave paddle. Note that the wave paddle in the numerical model is the front wall of the numerical flume. 


\subsection{Basic control equations}

The software ANSYS Fluent was chosen to solve the incompressible, Reynolds-Averaged form of the Navier-Stokes (RANS) equations. In which, the mass conservation equation and momentum equation are:

$$
\begin{aligned}
& \frac{\partial \bar{u}_{i}}{\partial x_{i}}=0 \\
& \rho \frac{\partial \bar{u}_{i}}{\partial t}+\rho \bar{u}_{j} \frac{\partial \bar{u}_{i}}{\partial x_{j}}=-\frac{\partial \bar{p}}{\partial x_{i}}+\mu \frac{\partial^{2} \bar{u}_{i}}{\partial x_{i} \partial x_{j}}-\frac{\partial \rho \overline{u_{i}^{\prime} u_{j}^{\prime}}}{\partial x_{j}}
\end{aligned}
$$

Where $\bar{u}_{i}=\frac{1}{\Delta t} \int_{t_{0}}^{t_{0}+\Delta t} u_{i} d t$ is the time average velocity, $u_{i}=\bar{u}_{i}+u^{\prime}$ is the water velocity. In which the indices $i$ and $j$ represent the direction of $(\mathrm{x}, \mathrm{y}, \mathrm{z})$ in the coordinate system. $\bar{P}$ is time-averaged pressure, $\rho$ is the density of fluid, and $\mu$ is the dynamic viscosity.

When the tsunami bore flows around the box-girder model, the Reynolds number is expected to be much large, i.e. around or larger than $1 e^{5}$, therefore a turbulence model is required. Wu (2017) compared the tsunami force on structure using different $k-\varepsilon$ turbulence models and pointed out that the $k-\varepsilon$ RNG model has higher calculation accuracy. Therefore, the $k-\varepsilon$ RNG turbulence model is adopted in this study. However, the tentative calculation indicates that wave attenuation is serious when the solitary wave propagates over the flat flume bottom. And the wave attenuation will be weak if the laminar model is used to calculate the propagation of the solitary wave over the flat flume bottom. Also the calculation efficiency is remarkably improved if the laminar model is used. Therefore, the laminar model is used before the solitary wave reaches the toe of the slop and the $k-\varepsilon$ RNG turbulence model is used when the solitary wave propagates on the slope and impacts the box-girder. The Scalable Wall Function is chosen to treat the boundary layer to avoid the degradation of the standard wall function when $y^{+}$is very small.

\subsection{Solitary wave theory}

Based the second-order solitary wave theory, the wave surface elevation $\eta$ and wave velocity $c$ can be obtained by Eqns. (3) and (4) respectively:

$$
\begin{aligned}
& \frac{\eta}{h}=\varepsilon \operatorname{sech}^{2} q-\frac{3}{4} \varepsilon^{2} \operatorname{sech}^{2} q \tan ^{2} q \\
& \frac{c}{\sqrt{g h}}=1+\frac{1}{2} \varepsilon-\frac{3}{20} \varepsilon^{2}
\end{aligned}
$$

Where $a$ is the wave height of solitary wave, $h$ is the water depth, and $g$ is the acceleration of gravity. In which, $\varepsilon=\frac{a}{h}$ is the relative wave height, $q=\frac{\sqrt{3 \mathcal{E}}}{2 h}\left(1-\frac{5}{8} \varepsilon\right)(x-c t)$ is the intermediate variable. The upstream sidewall of the numerical flume is set as stationary wall boundary, but it is forced to move back and forth under the control of UDF by using dynamic mesh technique. Namely the upstream sidewall can move back and forth, acting as a wave maker to generate solitary wave. The movement of the upstream 
sidewall is controlled by Eq. (5) proposed by Goring and Raichlen 1980, Goring and Raichlen 1992), which uses the target solitary wave surface equation to solve the position of upstream sidewall under shallow water conditions.

$$
\frac{d \xi(t)}{d t}=\bar{U}(\xi, t)=\frac{c \eta(\xi, t)}{h+\eta(\xi, t)}
$$

Equation (5) assumes the horizontal velocity of the water particles is a constant value in a certain depth, and the upstream sidewall speed is equal to the average velocity of the water particles in the certain water depth. In which $\xi$ is the position of the upstream sidewall, $t$ is time and $\eta$ is the wave surface elevation which is assumed to be:

$$
\eta(\xi, t)=a f(\theta)
$$

Where $f$ is the function of the phase angle $\theta, \theta=k(c t-\xi), k$ is the wave number. The implicit relation is available as:

$$
\xi(t)=\frac{a}{k h} \int_{0}^{\theta} f(\omega) d \omega
$$

Substituting the second-order solitary wave surface elevation Eq. (3) into Eq. (5), the position of the upstream sidewall $\xi$ can be calculated based on Eqs. (5) (7). Then the position is assigned to the upstream sidewall by UDF to control the motion of the upstream sidewall to generate solitary wave.

\subsection{Numerical model}

In this study, a three-dimensional numerical water flume is built, whose front view is shown in Fig. 1. The flume is with the total length of $47 \mathrm{~m}$, height of $1.2 \mathrm{~m}$, and width of $0.2 \mathrm{~m}$. The toe of the slope is $15 \mathrm{~m}$ away from the wavemaker, and the length of the horizontal projection of the slope is $12 \mathrm{~m}$, the center of the box-girder model is $2 \mathrm{~m}$ away from the top of the slop. The boundary condition of the flume top is set as Pressureoutlet to allow air flow in and out. The bottom, the downstream sidewall, and the lateral sidewalls of the flume, as well as the surface of the box-girder, are all set as stationary wall boundaries.

ANSYS ICEM is employed to build geometric model and generate grids. In the y direction, the computation domain is divided into 3 layers of grids uniformly. In the $\mathrm{z}$ direction, the grid size at the top is $\mathrm{d} z=0.3 \mathrm{~m}$, and gradually decreases to $\mathrm{d} z=0.02 \mathrm{~m}$ at the water free surface. And the grid size at the box-girder is refined to $\mathrm{d} z=0.002 \mathrm{~m}$. In the $\mathrm{x}$ direction, the grid size is uniform above the flat flume bottom, i.e. $\mathrm{dx}=0.3 \mathrm{~m}$. In the slope section, the grid size decreases to $\mathrm{dx}=0.02 \mathrm{~m}$ and the grid size further decreases to $\mathrm{dx}=0.002 \mathrm{~m}$ around the box-girder. In addition, the grid size downstream the upstream sidewall (wavemaker) is $\mathrm{dx}=0.03 \mathrm{~m}$. The grids around the box-girder are shown in Fig. 2 .

\subsection{Verification of numerical model}

This numerical model will be verified in two aspects: (1) verification of solitary wave deformation on the slop by comparing with theoretical wave deformation; (2) verification of solitary wave force by comparing with the experimental result. 


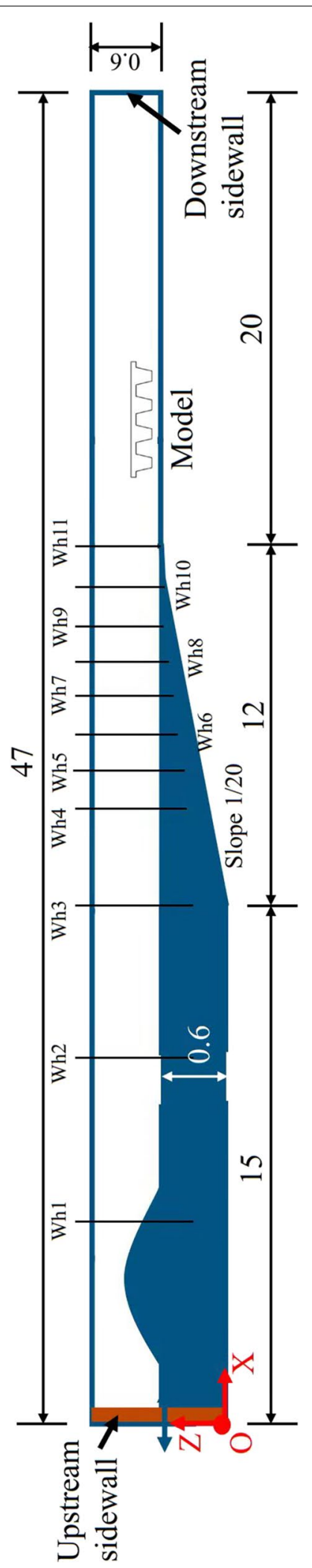

Fig. 1 Front view of the numerical wave flume (unit: $m$ ) 


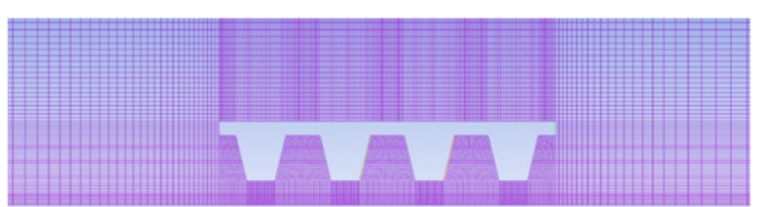

Fig. 2 Grids around the box-girder

(1) Verification of solitary wave deformation

The solitary wave with water depth $0.6 \mathrm{~m}$, wave height $0.12 \mathrm{~m}$ is selected as the case to validate the numerical model. The free surface height at $\mathrm{x}=5 \mathrm{~m}$ is measured in the numerical model and compared with its theoretical value, as shown in Fig. 3. It can be observed that the two curves are almost coincident with each other, which indicates that the 3D numerical wave flume built in this study can generate solitary wave accurately.

The solitary wave shoaling and breaking up on slope have been studied by many scholars. Grilli (1997) investigated the wave height and water depth during wave breaking, discussed the characteristics of various breaking types and made a clear classification of wave breaking, as shown in Eq. (8) and Table 1. In which $S$ is the breaking coefficient of the solitary wave, which can be used to determine the wave breaking type. $s$ is the gradient of the slope, $\varepsilon=a / h$ is the wave steepness, $a$ is the wave height and $h$ is the water depth measured from the flat flume bottom. Based on Eq. (8), the value of the breaking coefficient $S$ for the cases in this study can be calculated and results show $0.1<S<0.24$, which indicates that the wave breaking type of all the cases in this study is plunging breaking.

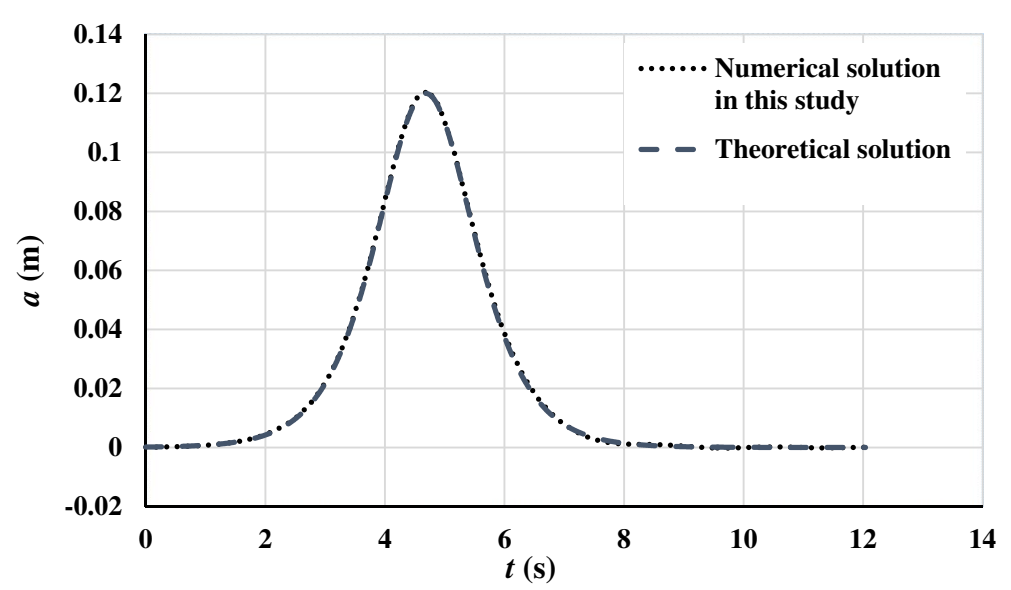

Fig. 3 Comparison of wave heights of solitary waves generated by the numerical method and the theoretical method (at $\mathrm{x}=5 \mathrm{~m}$ )

Table 1 Classification of wave-breaking proposed by Grilli (1997)

\begin{tabular}{lllll}
\hline$S$ & $S<0.025$ & $0.025<S<0.3$ & $0.3<S<0.37$ & $S>0.37$ \\
\hline Breaking type & Spilling breaking & Plunging breaking & Surging breaking & Un-broken
\end{tabular}




$$
S=1.521 \frac{s}{\sqrt{\varepsilon}}
$$

The water depth $h_{b}$ (measured vertically from the still water surface to the slope surface) at the location where solitary wave breaks on the slope can be estimated by the method suggested by Grilli (1997), as shown in Eq. (9). Hsiao et al. (2008) simulated the shoaling and breaking of solitary waves on a beach with a slope of $1 / 60$, and the experimental results agree well with that of Grilli (1997).

$$
\frac{h_{b}}{h}=\frac{0.149}{(S / \varepsilon)^{0.523}}
$$

A series of monitoring points named wh1 wh4 are set downstream of the wavemaker with $5 \mathrm{~m}$ interval in the flat flume bottom section, and a series of monitoring points named wh $5 \sim$ wh 11 are set from the toe of the slope with interval $1 \mathrm{~m}$ in $\mathrm{x}$ direction in the slope section, as shown in Fig. 1. The wave surface elevations of the monitoring points are shown in Fig. 4. It can be found that the wave height of the solitary wave almost remains unchanged along the flat flume bottom, indicating that the numerical flume can simulate solitary wave propagation considerably well. It also can be observed that the wave height of the solitary wave becomes large gradually, indicating the solitary wave steepens because of shoaling effect; and then the wave height decreases abruptly, indicating the solitary wave breaks.

The shoaling and breaking process of the solitary waves on the $1 / 20$ slope is shown in Fig. 5 . The wave surface becomes unsymmetrical about the wave crest when the solitary wave arrives at the toe of the slop, as shown in Fig. 5 (a). The wave front becomes steeper and even vertical, as shown in Fig. 5 (b) and (c). According to the geometric criterion of the breaking point (Grilli 1997; Chen et al. 2017), breaking occurs if the wave front is vertical. After that, the wave crest velocity continues to increase, then rolls down as a tongue and finally plunges into water, as shown in Fig. 5 (d) and (e). The breaking of the wave causes turbulence and tumbling of the water flow, entraps a large amount of air to form bubbles of different sizes, and the surge continues to propagate with the entrapped bubbles, as shown in Fig. 5 (f). These characteristics agree well with the description of the plunging breaking, which means that the numerical method in this study can simulate wave breaking considerably well.

In addition, the $\mathrm{x}$-coordinates of solitary wave breaking points in different cases are extracted and compared with the theoretical values by Eq. (9), as shown in Fig. 6. It can be observed that the difference between the numerical solution and theoretical solution is within $1 \mathrm{~m}$, indicating the numerical model in this study can simulate the shoaling and breaking of solitary waves on slopes considerably well.

\section{(2) Verification of solitary wave force}

The experimental data of Huang et al. (2019) was used to verify solitary wave force calculation accuracy by the numerical model in this study. A wave flume and a boxgirder model, which are completely the same as that in the physical experiment, were built numerically. And the same case, i.e. the case with water depth $0.623 \mathrm{~m}$, submergence ratio 0 and wave height $0.167 \mathrm{~m}$, was conducted in the verification. The 
Yang et al. Advances in Bridge Engineering

(2021) 2:28

Page 9 of 29

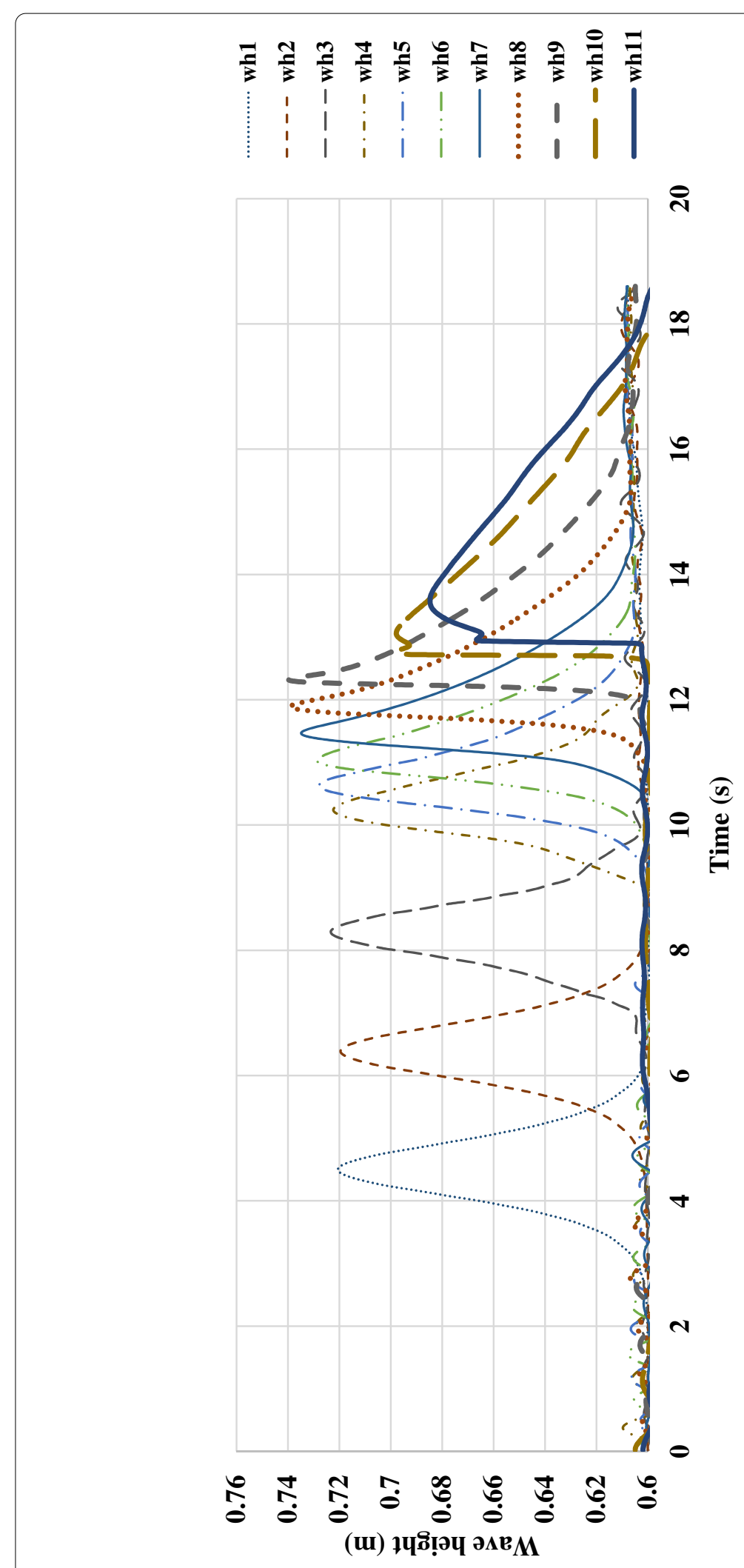

Fig. 4 Wave surface elevation time histories at the different monitoring points 

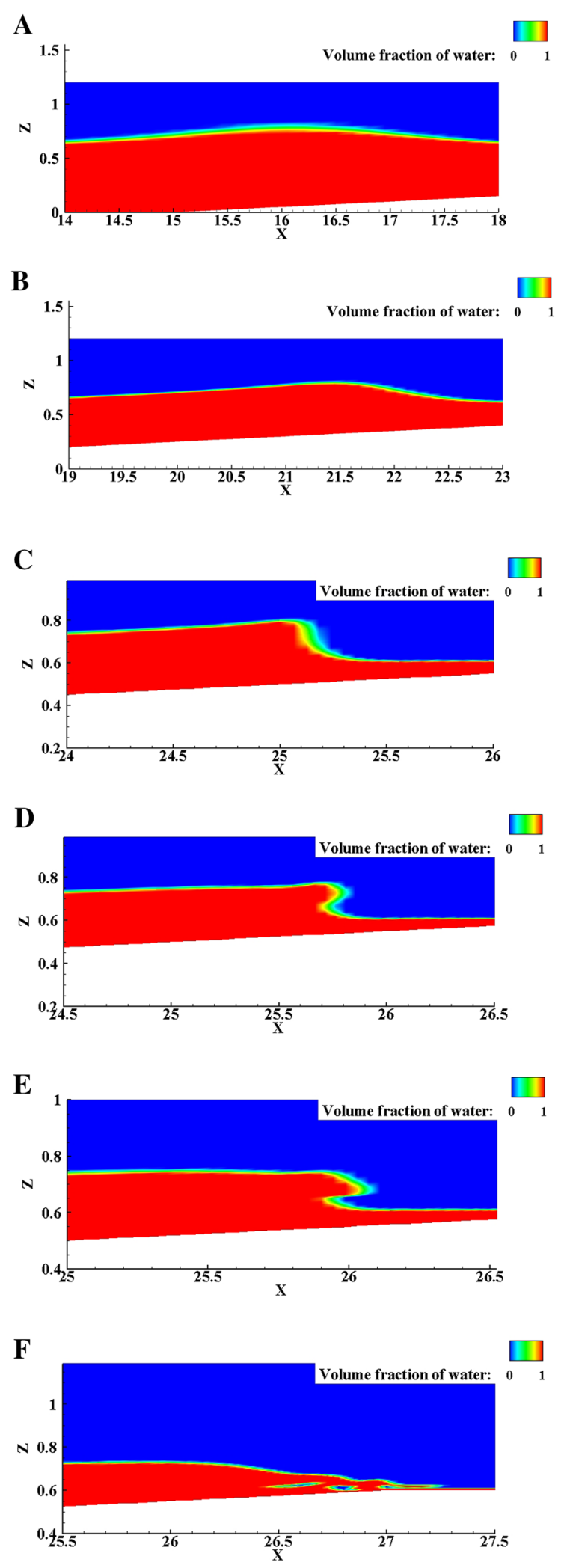

Fig. 5 Phase contours when the solitary wave propagates on the 1/20 slope in the case with $h=0.6 \mathrm{~m}, a=$ $0.12 \mathrm{~m}: \mathbf{a} t=8.00 \mathrm{~s}, \mathbf{b} t=10.00 \mathrm{~s}, \mathbf{c} t=11.50 \mathrm{~s}, \mathbf{d} t=11.71 \mathrm{~s}, \mathbf{e} t=11.86 \mathrm{~s}, \mathbf{f} t=12.20 \mathrm{~s}$ (units of axes: $\mathrm{m}$ ) 


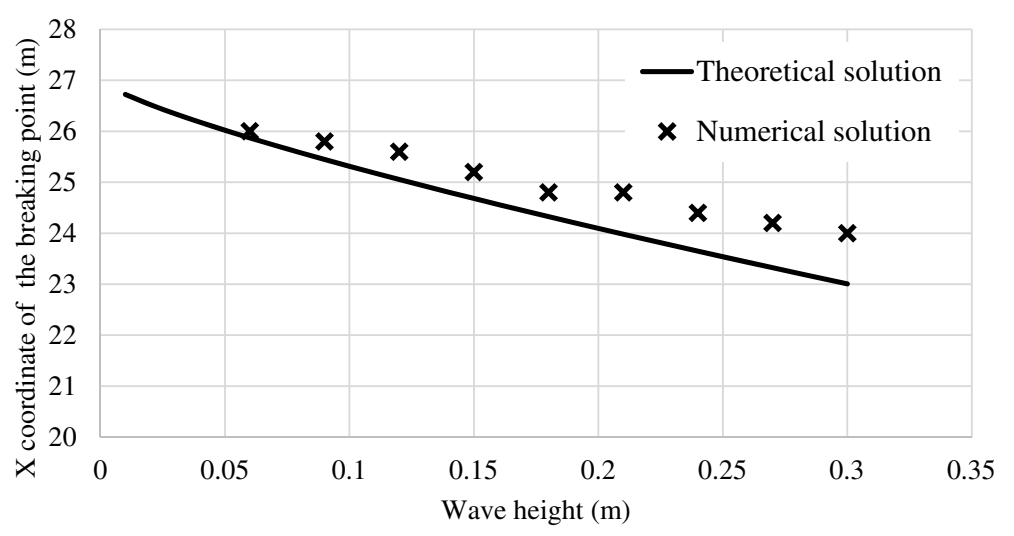

Fig. 6 Compare of the $x$ coordinates of the breaking point between numerical solution in this study and theoretical solution by Grilli et al. (1997)

in-line wave forces $F_{x}$ calculated by the numerical method in this study and measured by Huang et al. (2019) are compared in Fig. 7 (a), and correspondingly the vertical wave forces $F_{z}$ are compared in Fig. 7 (b). It can be observed that the solitary forces obtained by the numerical method agree well with that measured in the physical experiments by Huang et al. (2019), indicating the numerical method used in this study can calculate wave force on structures accurately.

Generally, the verification implies that the turbulence model, wall function and boundary conditions, grid size and other parameters used in the numerical simulation are correct and can be used for simulation of tsunami bore force.

\section{Characteristics of breaking solitary wave force on box-girder}

\subsection{Numerical model of box-girder and calculation cases}

The box-girder bridge with span of $20 \mathrm{~m}$ and width of $12 \mathrm{~m}$, which is widely used in coastal areas of China, is selected as prototype in this study. The scale ratio $\lambda=1: 40$ (length scale) is used to scale down the superstructure of the prototype bridge, then the box-girder model is obtained and shown in Fig. 8. In which, the surface of the box-girder is decomposed into multiple panels. This method, which has been employed by Xu et al. 2016 and Yang et al. 2020., can facilitate analyzing the contribution of each panel to the entire force.

The initial water depth is set as $h=0.6 \mathrm{~m}$, i.e. the water surface is aligned to the top of the slope. The horizontal distance between the center of the box-girder and the top of the slope is $2 \mathrm{~m}$, which remains unchanged in this study. The solitary wave height changes from $a=9 \mathrm{~cm}$ to $a=30 \mathrm{~cm}$ with the increment of $3 \mathrm{~cm}$. The clearance of the box-girder (the distance from the still water level to the bottom of the box-girder) ranges from $Z=1 \mathrm{~cm}$ to $Z=5 \mathrm{~cm}$ with the increment $1 \mathrm{~cm}$. All the wave height and clearance pairs used in the cases in this study are listed in Fig. 9. When $Z \geq 4 \mathrm{~cm}$ and $a \leq 0.15 \mathrm{~cm}$, breaking solitary wave cannot impact the bridge girder, therefore the corresponding cases are not involved here. 

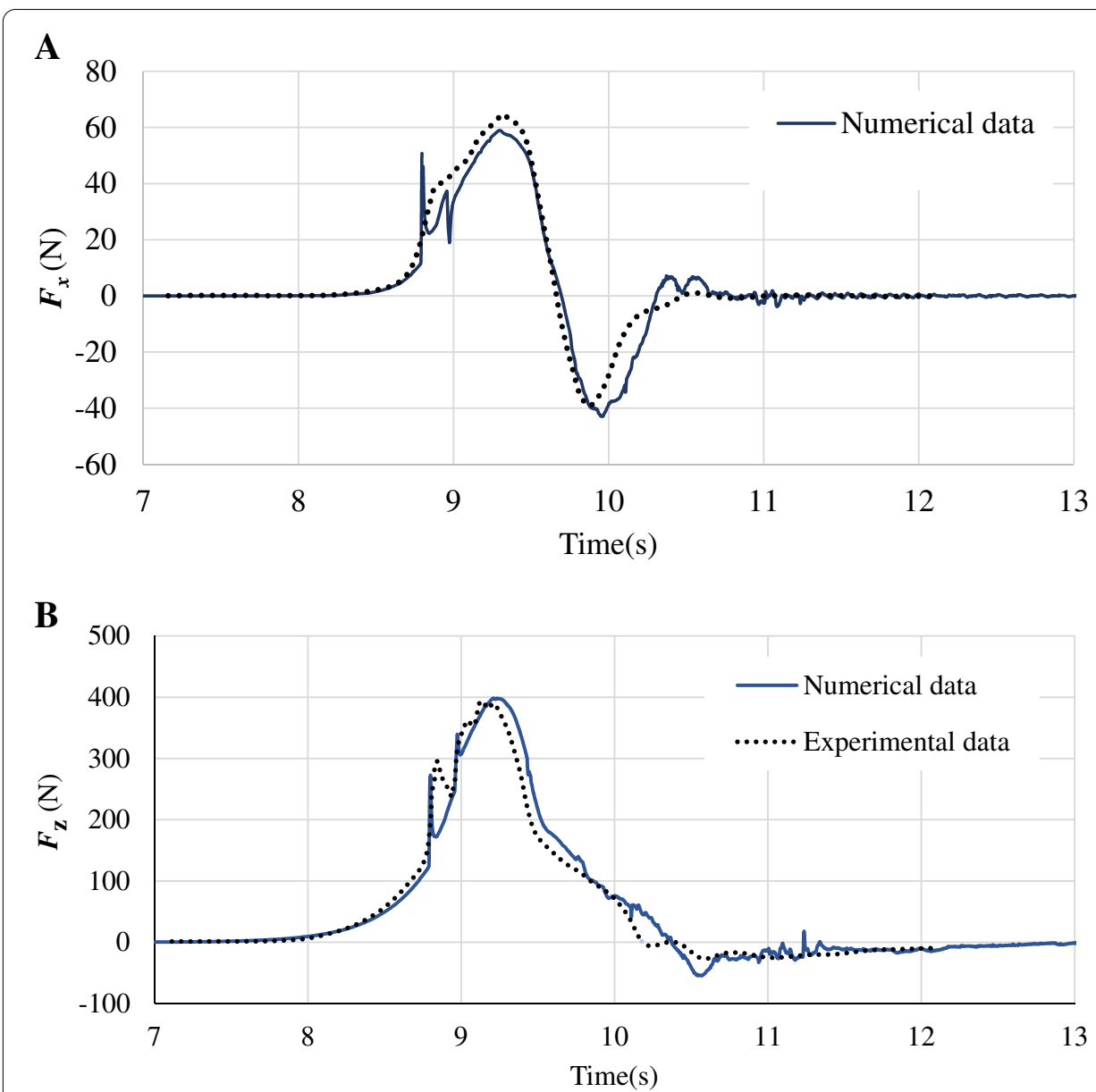

Fig. 7 In-line wave force comparison (a) and vertical wave force comparison (b) between the numerical method by this study and the experimental data measured by Huang et al. (2019)

\subsection{Characteristics of tsunami bore forces}

The case with $h=0.6 \mathrm{~m}, Z=2 \mathrm{~cm}, a=18 \mathrm{~cm}$ is selected as a representative to discuss the characteristics of tsunami bore force on box-girder. The time history of the in-line force, as shown in Fig. 10 (a), can be divided into three stages according to its characteristics, i.e. (I) bottom flow stage, (II) initial impinging stage and (III) second impinging stage. The characteristics of the three stage are as follows:

(I) Bottom flow stage $(t=12.82 \mathrm{~s} \sim 13.33 \mathrm{~s})$ : the stage lasts from the instant when the bore reaches the horizontal position of the panel S1 to the instant when the bore touches the panel S3 and generates horizontal force on S3 abruptly. In this stage, the horizontal force is almost zero since the bore cannot impact the girder and just flows under the girder rib. With the increase of wave height or with the decrease of clearance, the duration of this stage decreases or even disappears.

(II) Initial impinging stage $(t=13.33 \mathrm{~s} \sim 13.74 \mathrm{~s})$ : the stage lasts from the instant when the bore impacts the box-girder to generate horizontal force to the instant when the horizontal force reaches its first trough. In this stage, the horizontal force 


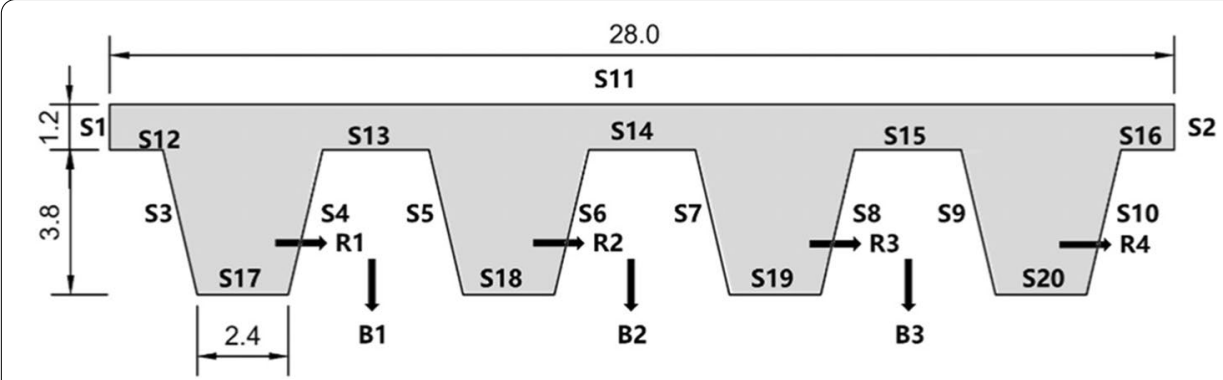

Fig. 8 Cross-section of the box-girder, and the girder surface is decomposed into panels named in the form of "SN". The ribs and chambers are named in the form of "RN" and "BN" respectively. In which " $\mathrm{N}$ " is the number of the panel, rib or chamber. (unit: $\mathrm{cm}$ )

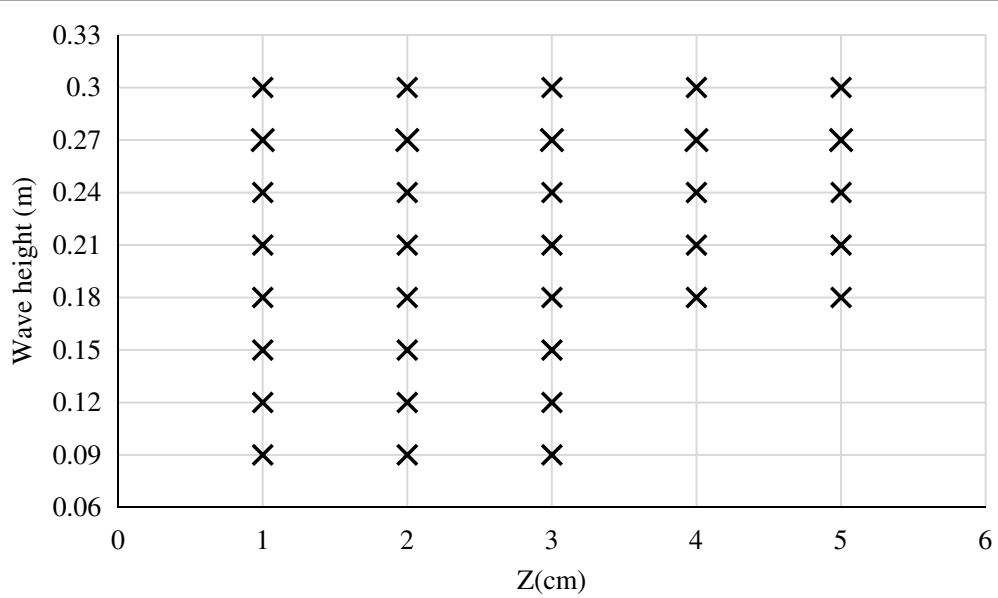

Fig. 9 Solitary wave height and clearance pairs in the cases in this study

increases sharply until reaching its first peak, and then it decreases to its first trough.

(III) Second impinging stage $(t>13.74 \mathrm{~s})$ : the stage starts from the instant when the horizontal force reaches its first trough, and ends when the bore completely passes through the box-girder. In this stage, the in-line tsunami force experiences the second impinging and gradually decreases.

Time history of the vertical force on box-girder is shown in Fig. 10 (b), which can be divided into four stages accordingly, i.e. (I) bottom flow stage, (II) chamber being enclosed stage, (III) initial impinging stage and (IV) second impinging stage. Note that the first two stages are the same as that of the in-line force. The characteristics of the four stages are:

(I) Bottom flow stage ( $t=12.82 \mathrm{~s} \sim 13.33 \mathrm{~s})$ : in this stage, the bore continuously rises and contacts the bottom of the beam ribs but no tsunami bore impinges on the upstream panels.

(II) Chamber being enclosed stage ( $t=13.33 \mathrm{~s} \sim 13.74 \mathrm{~s})$ : in this stage, a small quantity of tsunami bore impinges on the panels S3 and S12, generating slightly positive 


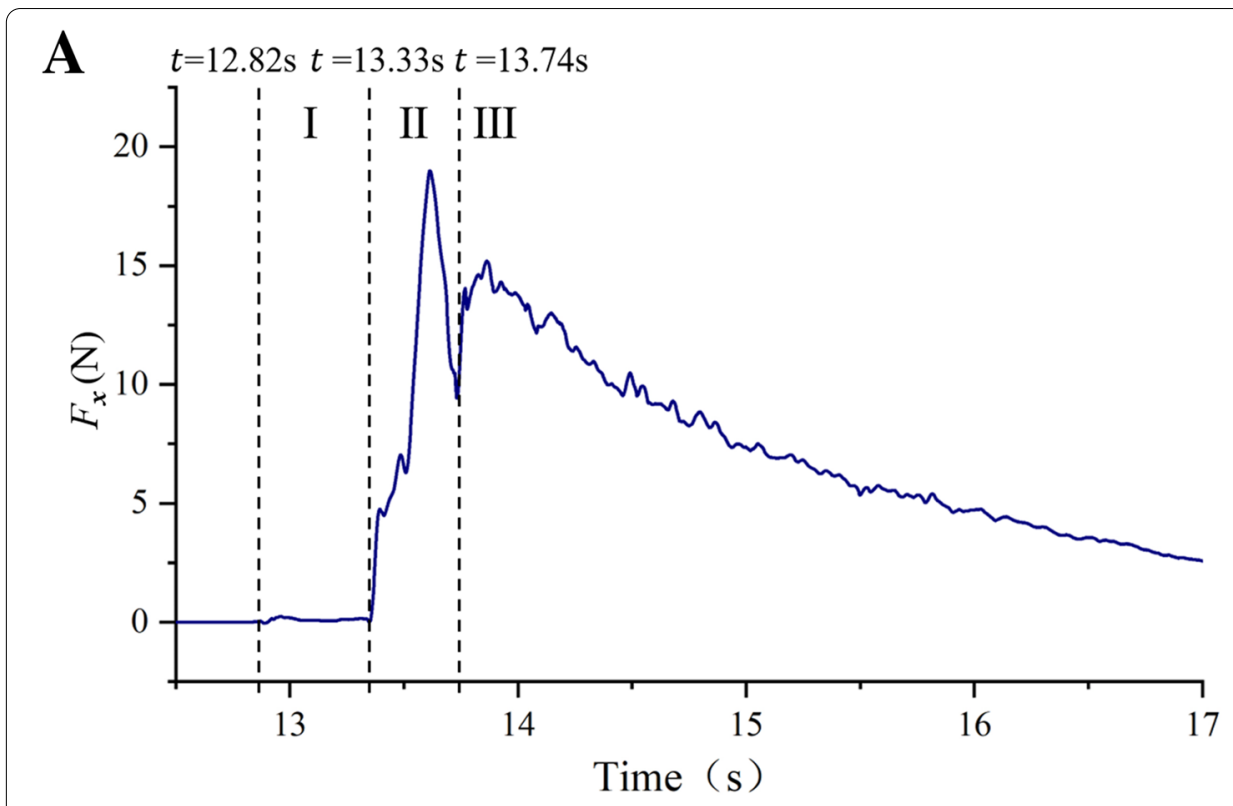

\section{B}

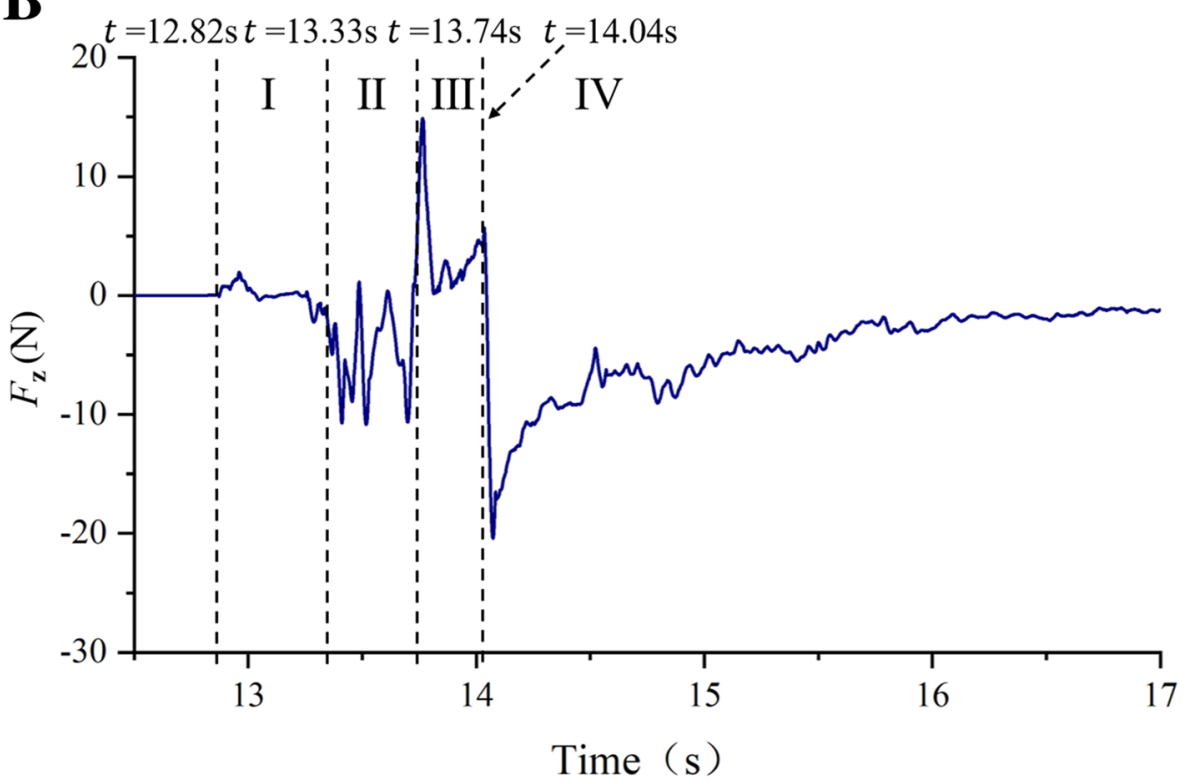

Fig. 10 Time histories of the in-line force (a) and the vertical force (b)

vertical force. Simultaneously the chambers are enclosed by water flowing below the girder, the oscillation of entrapped air in chambers generates negative and fluctuating vertical force on box-girder.

(III) Initial impinging stage $(t=13.74 \mathrm{~s} \sim 14.04 \mathrm{~s})$ : in this stage, the upstream panels S1 and S3 are impacted by a great quantity of tsunami bore, resulting in a positive peak value of the vertical force.

(IV) Second impinging stage $(t>14.04 \mathrm{~s})$ : in this stage, the bore overtopping the boxgirder deck strikes the top panel S11, resulting a downward impacting force, i.e. the 
A

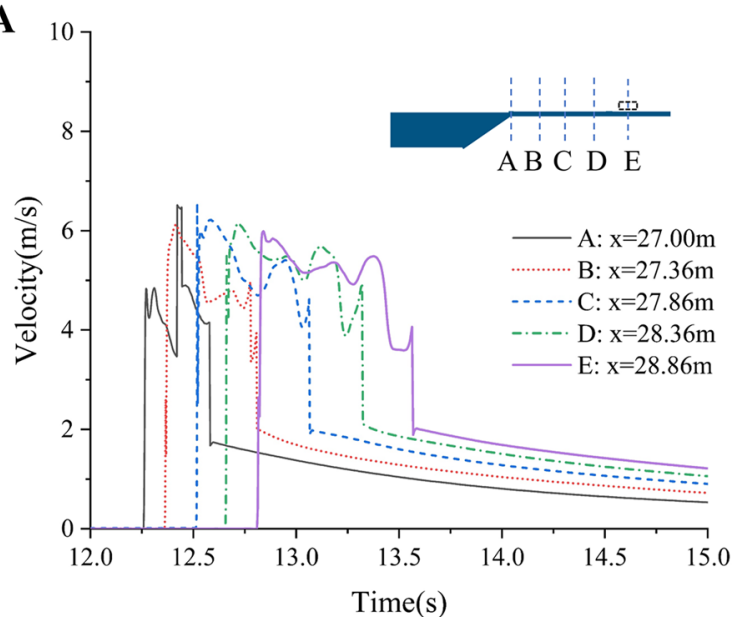

B

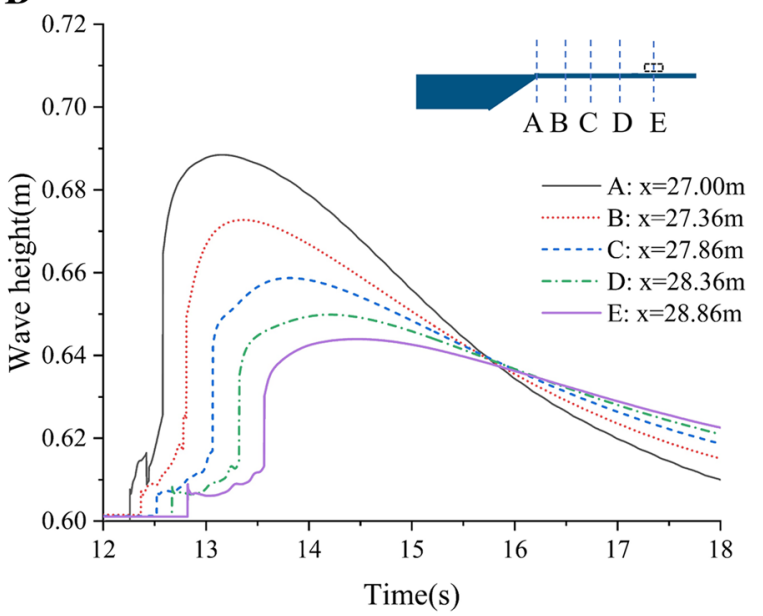

Fig. 11 Flow velocity time histories (a) and bore height time histories (b) at different monitoring locations

vertical force reaches the largest negative value. And with the green water falling down from the top panel S11, the vertical force increases to zero gradually.

\subsection{Analysis of tsunami bore force generation mechanism}

The cross-section averaged flow velocity time-histories of the tsunami bore at positions $\mathrm{A} \sim \mathrm{E}$ located between the slope top and box-girder are shown in Fig. 11 (a), correspondingly the averaged wave height time histories of these locations are shown in Fig. 11 (b). It can be found that the cross-section averaged flow velocity suddenly increases when the tsunami bore arrives at the monitoring locations, and the velocity decreases slightly with several fluctuations within a certain time, then the velocity suddenly decreases to a small value, i.e. around $2 \mathrm{~m} / \mathrm{s}$, indicating the main body of the tsunami bore has passed through the monitoring location, at last the velocity gradually decreases to zero. 
It can also be found that at the point near to the slope top, i.e. the location at $\mathrm{x}=27.00 \mathrm{~m}$, the tsunami bore height is about $1.5 \mathrm{~cm}(61.5 \mathrm{~cm} \sim 60 \mathrm{~cm})$ when the tsunami bore arrives, and the bore height increases sharply to about $9 \mathrm{~cm}$ later. However, at the position farther from the slope top, i.e. the position at about $\mathrm{x}=28.86 \mathrm{~m}$, the bore height increases $4 \mathrm{~cm}(64 \mathrm{~cm} \sim 60 \mathrm{~cm})$ suddenly and then decreased slowly.

As mentioned in the second section, when the plunging wave breaks, the wave crest velocity increases, and rolls down as a tongue, as shown in Fig. 5 (d) and (e). After the wave breaks, the water tongue collapses into the downstream to form a surge, which is composed of air bubbles and water, and propagates forward with higher flow velocity and smaller surge height, as shown in Fig. 5 (f). This is also the reason why the velocity increases sharply when the bore arrives at the monitoring position, as shown in Fig. 12 (a), but the bore height increases slightly and remains unchanged in a certain time before increasing sharply, as shown in Fig. 12 (b).

The time history curves of bore height, flow velocity, and tsunami force are normalized by their maximum values respectively, and compared in Fig. 12. It demonstrates that time when the drag force increases suddenly is coincident with that of bore height, and the positive peak of the vertical force happens around the time when bore height reaches its maximum, which implies that the drag force and the maximum of vertical force are dominated by bore height. Just as discussed in last paragraph, before sudden increases of drag force and vertical force, the bore has larger velocity but fewer contribution to drag force, and only cause downward fluctuation to vertical force. Because during this stage the bore height is small enough to be able to flow under the girder ribs.

In the following paragraph, the contributions of the panels (defined in Fig. 8) to the peak values of the horizontal and vertical forces will be discussed in detail to explore their generation mechanism.

\section{(1) First peak of horizontal force $(t=13.62 \mathrm{~s})$}

At the beginning, the bore directly flows under girder ribs and fails to impact on girder panels because the bore height is smaller than the clearance. As the bore height increases, the panel S3 is impacted, and the horizontal force sharply increases and then reaches the first peak value. At this time, part of the bore flow downstream under the girder, and part of the bore blocked by the panel S3 begins to roll upstream and impacts the panel S12, as shown in Fig. 13 (a). Figure 13 (b) shows the contribution of each panel to the horizontal force at $t=13.62 \mathrm{~s}$. It can be seen that the horizontal force is almost provided by the panel S3. In Fig. 13 (b) the contribution rate is defined as $R_{x-\max -i}=\frac{F_{x i}}{F_{x-\max }} \times 100 \%, F_{x i}$ and $F_{x-\max }$ are horizontal forces on the panel S3 and on the whole girder respectively. The static pressure, dynamic pressure and total pressure contours at $t=13.62 \mathrm{~s}$ are shown in Fig. 14. It can be observed that the horizontal force on S3 is mainly generated by static pressure. Note that the pressure in the chambers B1, B2, and B3 are all negative (relative to the atmosphere pressure). Therefore the panels S4, S6 and S8 contribute positive horizontal force, while the panels S5, S7 and S9 contribute negative horizontal force. And the negative pressure in the upstream chamber is larger than that in the downstream chambers, 


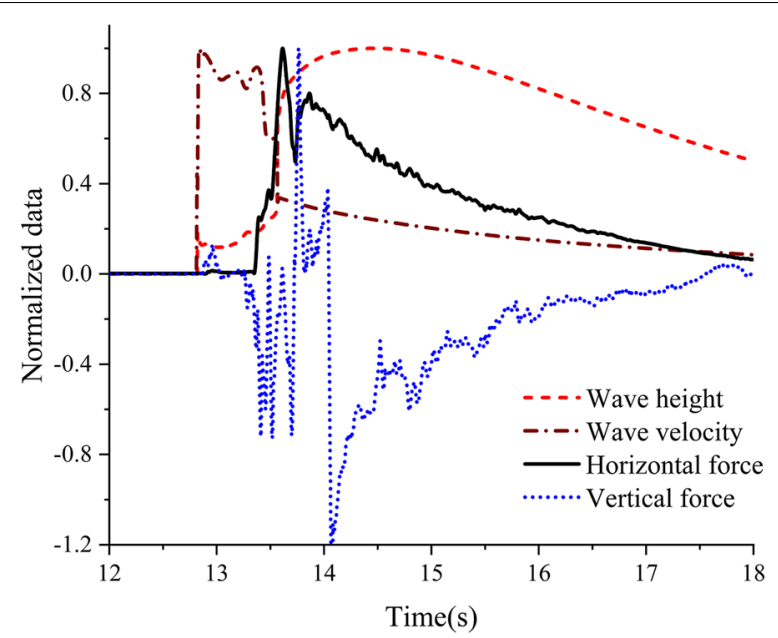

Fig. 12 The relationship between tsunami force, bore height and bore velocity at $x=28.86 \mathrm{~m}$ (each data is normalized by its maximum value)

i.e. $\left|P_{\mathrm{B} 1}\right|>\left|P_{\mathrm{B} 2}\right|>\left|P_{\mathrm{B} 3}\right|$. Generally the resultant force of the two opposite panels in one chamber, for example the panels S4 and S5 in chamber B1, is approximately zero (fewer contribution to the entire horizontal force) because the horizontal forces on the two panels counteract with each other.

(2) Second peak of horizontal force $(t=13.86 \mathrm{~s})$

As the runup on the upstream panels continues to increase, the horizontal force continues to increase until it reaches the second peak, as shown in Fig. 12. When the runup height is larger than the panel S1, the bore begins to overtop the girder deck and then overturns downstream, as shown in Fig. 15 (a). At $t=13.86 \mathrm{~s}$, the horizontal force on the girder is mainly contributed by the panels S3 and S1, whose contribution rates are $85 \%$ and $14 \%$ respectively, as shown in Fig. 15 (b). At the moment, the chambers B1, B2, and B3 are already closed and the air pressure in chambers is positive. Therefore the panels S4, S6 and S8 generate negative horizontal forces, while the panels S5, S7 and S9 generate positive horizontal forces. But it is obvious that the force on S5 is greater than S4, and S7 is greater than S6. This is because a part of the water directly impacts the panels S5 and S7, as shown in Fig. 15 (a), making the horizontal force on the two panels larger. The static pressure, dynamic pressure and total pressure contours at $t=13.86 \mathrm{~s}$ are shown in Fig. 16. It demonstrates that the horizontal forces on the panels S3 and S1 are mainly caused by the static pressure.

(3) Positive peak of vertical force $(t=13.75 \mathrm{~s})$

When the bore wave impacts the girder, part of the bore flows from the bottom of the girder and closes the chambers B1, B2, and B3 gradually, exerting positive pressure in the chambers; part of the bore is blocked by the panels S3, S12 and S1, running up along 

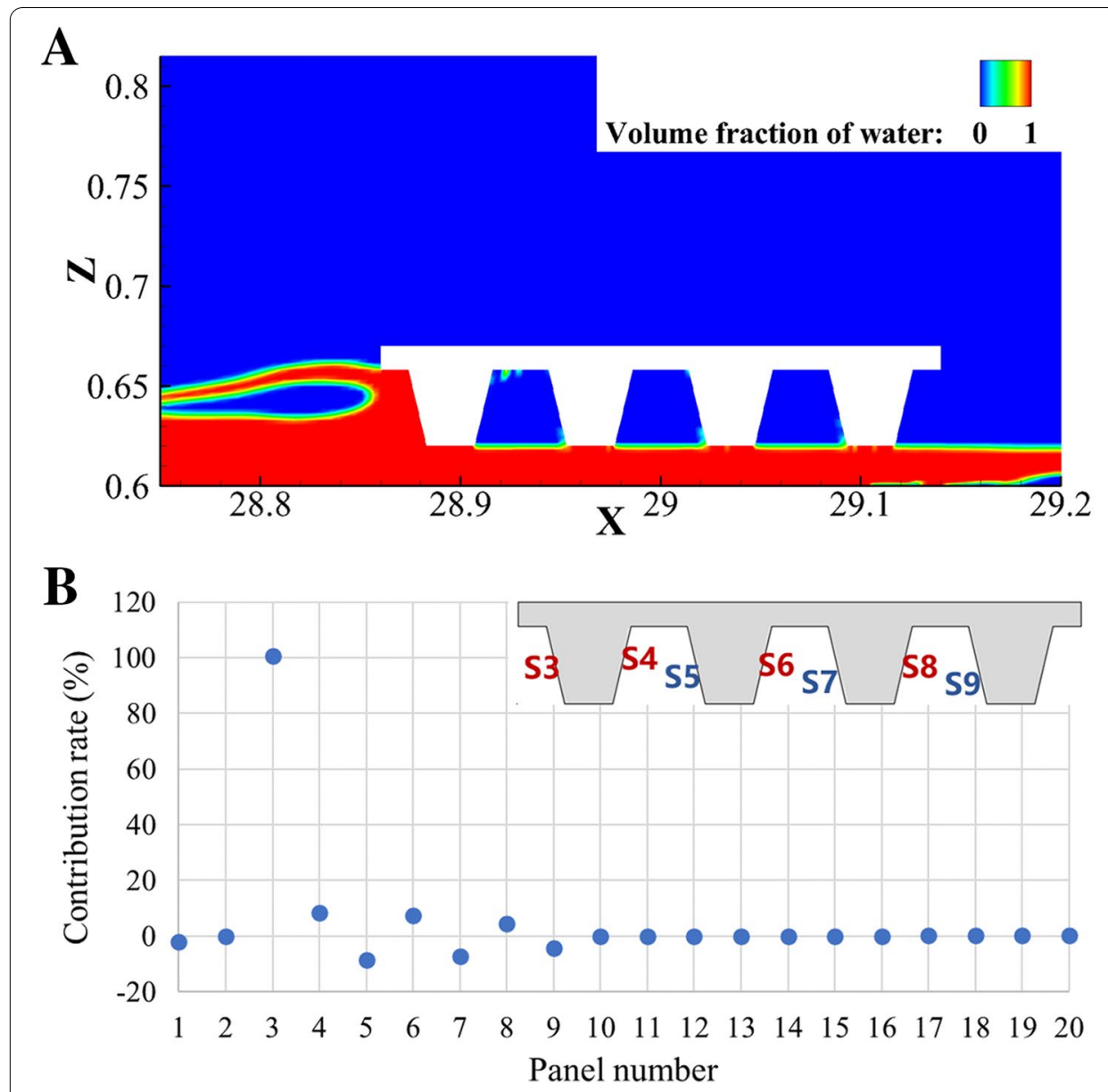

Fig. 13 Phase contour (a) and the contribution rate of each panel to the horizontal force at $t=13.62 \mathrm{~s}(\mathbf{b})$

these panel, as shown in Fig. 17 (a). At $t=13.75 \mathrm{~s}$, the vertical force reaches its positive peak value, and the contribution of each panel to the vertical force is shown in Fig. 17 (b). Among them, the main contributors are S12 and S3, whose contribution rates are $20.65 \%$ and $15.76 \%$ respectively. In addition, the panels S17, S18, S19 and S20 contribute positive vertical force. The closer to the upstream surface of the girder, the larger the contribution rate except of the panel S17 because a recirculation zone is formed under the panel S17, which introducing a lower pressure, as shown in Fig. 20 (b) and Fig. 18 (a).

At the same time, all the panels in the chambers suffer positive vertical force because the air pressure in these chambers are positive. The closer to the upstream surface, the larger the air pressure in chamber because the runup height on the upstream surface is the main determinant of the air pressure. Therefore, the contribution rate of S13 is larger than S14, and S14 is larger than S15. And in one chamber, the horizontal panel has larger contribution rate than the inclined panels because the former has larger projection area on horizontal axis, for example S13 > S4, as shown in Fig. 17 (b).

The static pressure, dynamic pressure and total pressure contours at $t=13.75 \mathrm{~s}$ are shown in Fig. 18. It can be observed that the vertical forces is mainly contributed by the panels S3 and S12, which suffer considerably larger static pressure when impacted by bore front. It can also be observed that air pressures in chambers are in order: 

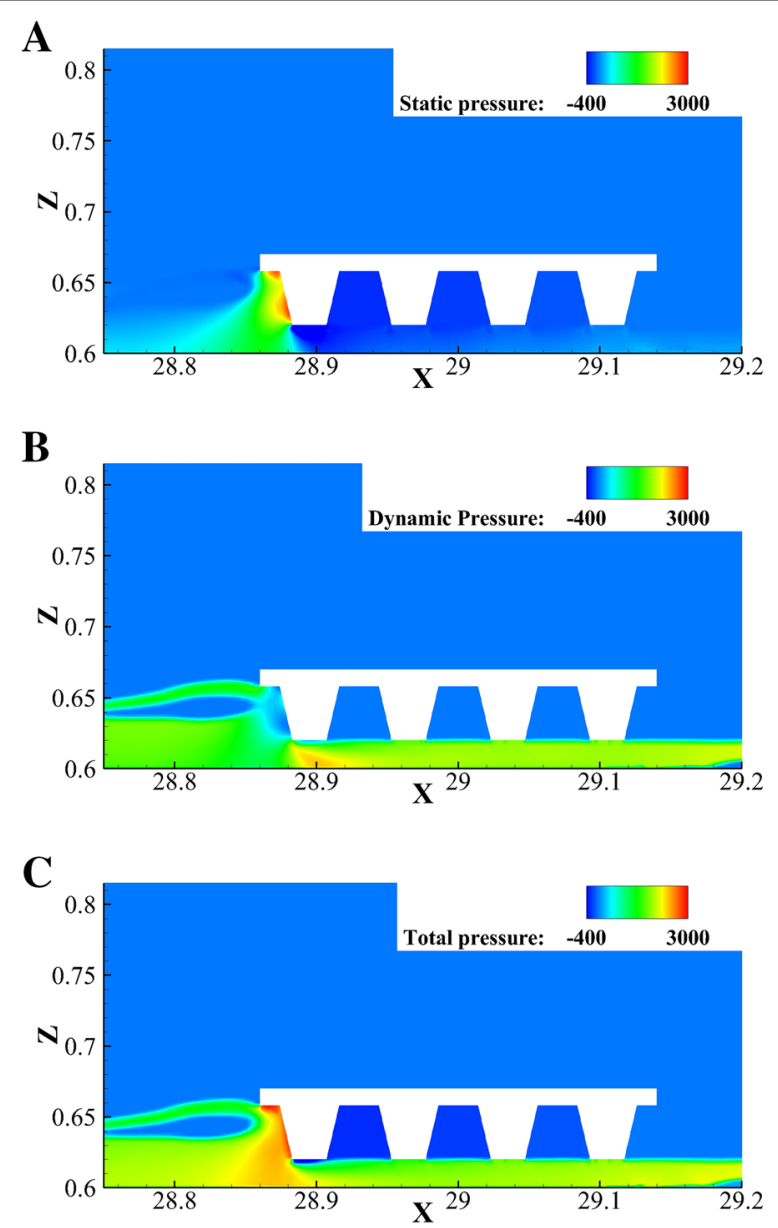

Fig. 14 Static pressure (a), dynamic pressure (b) and total pressure (c) at $t=13.62 \mathrm{~s}$ (units of axes: $\mathrm{m}$, unit of pressure: $\mathrm{Pa}$ )

$\mathrm{P}_{\mathrm{B} 1}>\mathrm{P}_{\mathrm{B} 2}>\mathrm{P}_{\mathrm{B} 3}$, which supports the discussion in last paragraph that contribution of S13 is larger than S14, and S14 is larger than S15.

(4) Negative peak of vertical force $(t=14.058 \mathrm{~s})$

When $t=14.058 \mathrm{~s}$, the bore overturns downstream and forms a water tongue. The water tongue finally impacts the girder deck, i.e. the panel S11, as shown in Fig. 22 (a), exerting an extremely large pressure on the panel S11, as shown in Fig. 20 (c). Simultaneously a part of air was entrapped by water tongue and the panel S11, the entrapped air is pressed by the rushing down tongue and exerts considerably large pressure on the panel S11, as shown in Fig. 20 (c). Therefore the panel S11 suffers a large downward force, which makes the negative vertical force on the girder to be the largest, as shown in Fig. 12, i.e. the contribution of S11 is dominant, as shown in Fig. 19 (b). On the panel S11, because the stressed area of the direct impacting of water tongue is smaller than that of entrapped air, the contribution rate of the former is believed to be smaller than the latter. The panels S13 and S17 contribute non-negligible negative vertical forces and the panels S3 and S12 contributes relatively larger positive vertical forces. 


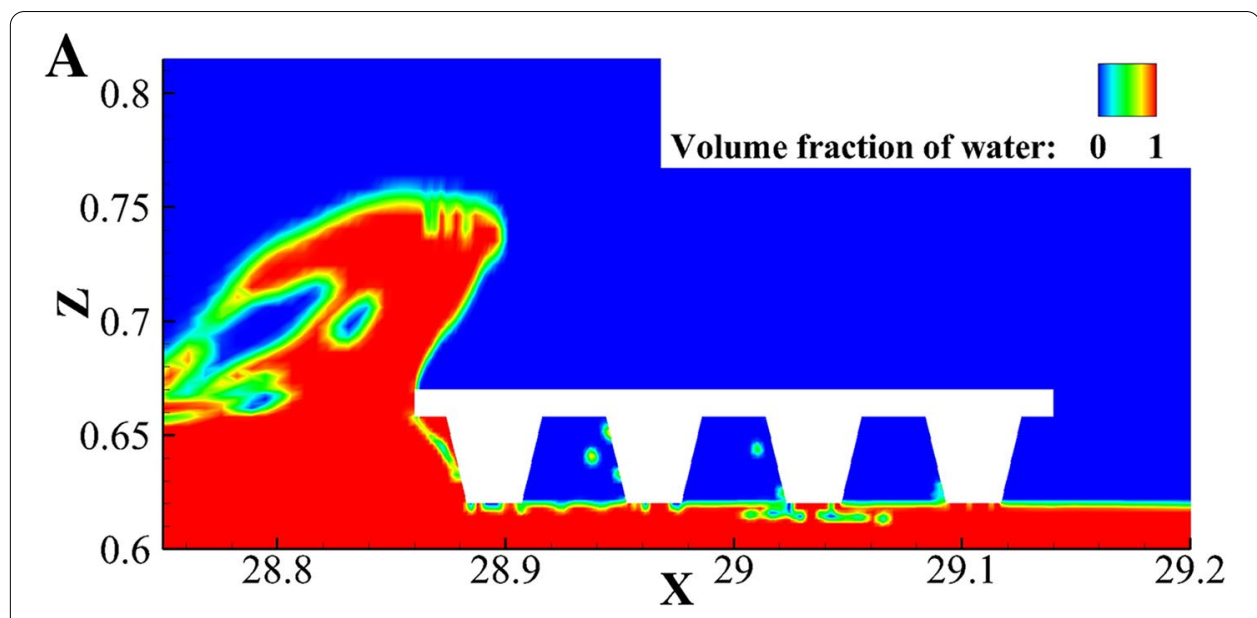

B

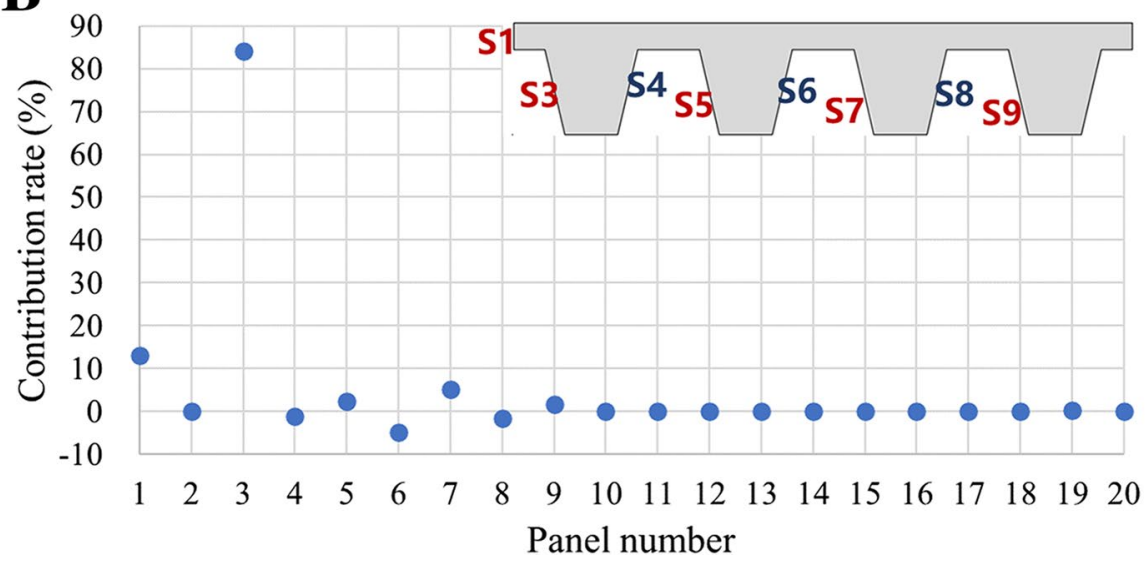

Fig. 15 Phase contour (a) and the contribution rate of each panel to the horizontal force at $t=13.86 \mathrm{~s}(\mathbf{b})$

The static pressure, dynamic pressure and total pressure at $t=14.058 \mathrm{~s}$ are shown in Fig. 20. It can be observed that the vertical force is dominated by static pressure. In real practice, when the water tongue impacts the girder deck, air could escape more obviously because the shape of water tongue is complex in the longitudinal direction (the direction perpendicular to the paper in Fig. 22 (a)) and cannot impact bridge deck simultaneously, so only a part of air could be captured. In other words, the negative vertical force on the panel S11 in real practice should be smaller than that in this numerical simulation.

\section{Influence of solitary wave height on tsunami bore force}

The water depth and clearance remains unchanged, i.e. $h=0.6 \mathrm{~m}$ and $Z=2 \mathrm{~cm}$, the solitary wave height $a$ changes from $0.15 \mathrm{~cm}$ to $0.3 \mathrm{~cm}$ with increment $0.03 \mathrm{~cm}$. The time histories of horizontal forces of these cases are compared in Fig. 21. It can be observed that with the increase of the wave height, the peak value of the horizontal force occurs earlier, and the time interval between the first and second peak values becomes smaller, 

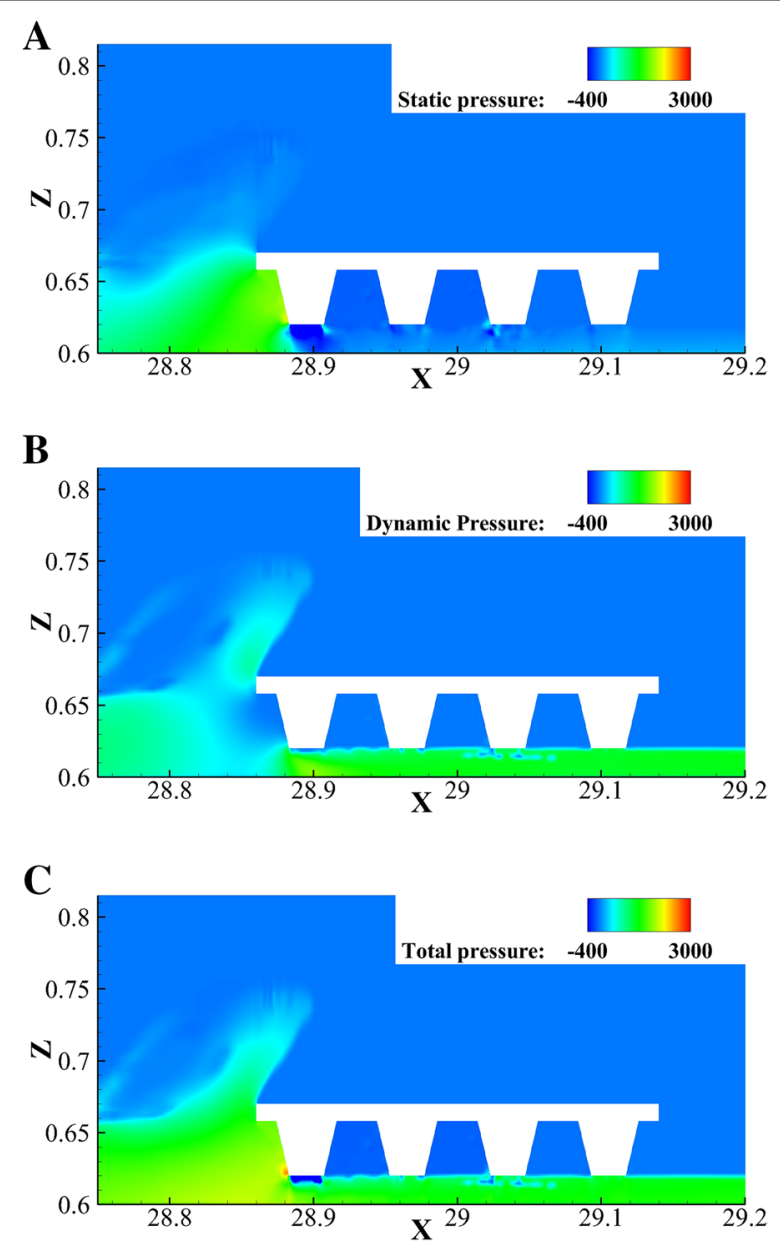

Fig. 16 Static pressure (a), dynamic pressure $(\mathbf{b})$ and total pressure $(\mathbf{c})$ at $t=13.86 \mathrm{~s}$ (units of axes: $\mathrm{m}$, unit of pressure: Pa)

as shown in Fig. 21. This is because the larger the wave height, the larger the tsunami bore velocity after the solitary wave breaks.

The first and the second peak values of the horizontal force, i.e. $F_{x-\max }^{i m p(f)}$ and $F_{x-\text { max }}^{i m p(s)}$ respectively, changing with wave height, are shown in Fig. 22 (a). It demonstrates that $F_{x-\max }^{i m p(f)}$ and $F_{x-\max }^{i m p(s)}$ monotonically increase with wave height. This is because the horizontal peak force is mainly caused by the impacting pressure on the upstream panel S3. The impacting pressure increases with the bore height, and the bore height increases with solitary wave height. However, the horizontal force peak value does not increase with wave height linearly because the solitary wave breaking position, the air entrapped in the wave breaking process and the tsunami bore shape don't change linearly with solitary wave height strictly.

The vertical force time histories of the cases with different solitary wave height are similar as that in Fig. 13, which are omitted intentionally here. The positive and negative peak values of the vertical forces with different solitary wave height, i.e. $F_{z-\max }^{i m p(+)}$ and $F_{z-\max }^{i m p(-)}$ respectively, are compared in Fig. 22 (b). The positive peak value of the vertical force $F_{z-\max }^{i m p(+)}$, which is mainly contributed by the static pressure on $\mathrm{S} 3$ and 


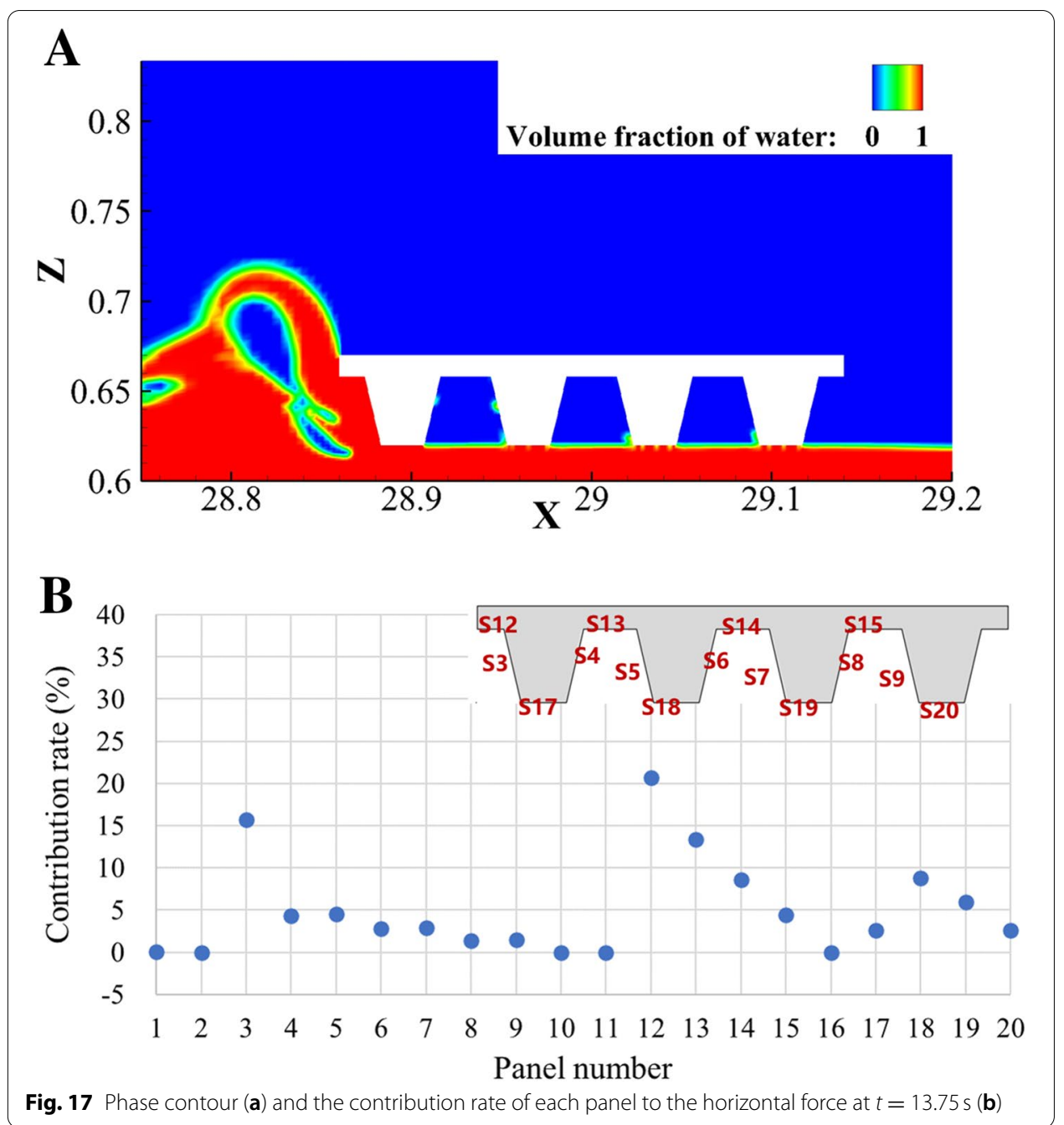

S12, increases with wave height. The negative peak value of the vertical force $F_{z-\max }^{i m p(-)}$ increases with wave height when $a \leq 0.24 \mathrm{~m}$. This is because with the increase of solitary wave height, not only the bulk of overturning water volume increases, but also the runup height increases, which makes the water tongue over the bridge deck with greater potential energy and impacts the girder deck with greater kinetic energy when it overturns, resulting in a greater impacting force on the panel S11. When the wave height is greater than a certain level, i.e. $a>0.24 \mathrm{~m}$, the water tongue has enough kinetic energy to partly stride over the girder deck when it overturns, as shown in Fig. 23, therefore only part of the water tongue impact the panel S11, resulting in a decrease in the negative peak value of the vertical force, as shown in Fig. 22 (b).

Similarly, the positive peak value of the vertical force fails to changes linearly with solitary wave height as the solitary wave breaking position, bore front shape and the entrapped air involved in the breaking process are nonlinearly changed with solitary wave height, which introduce a certain fluctuation to the change trend of the vertical force peak value, as shown in Fig. 22 (b). 

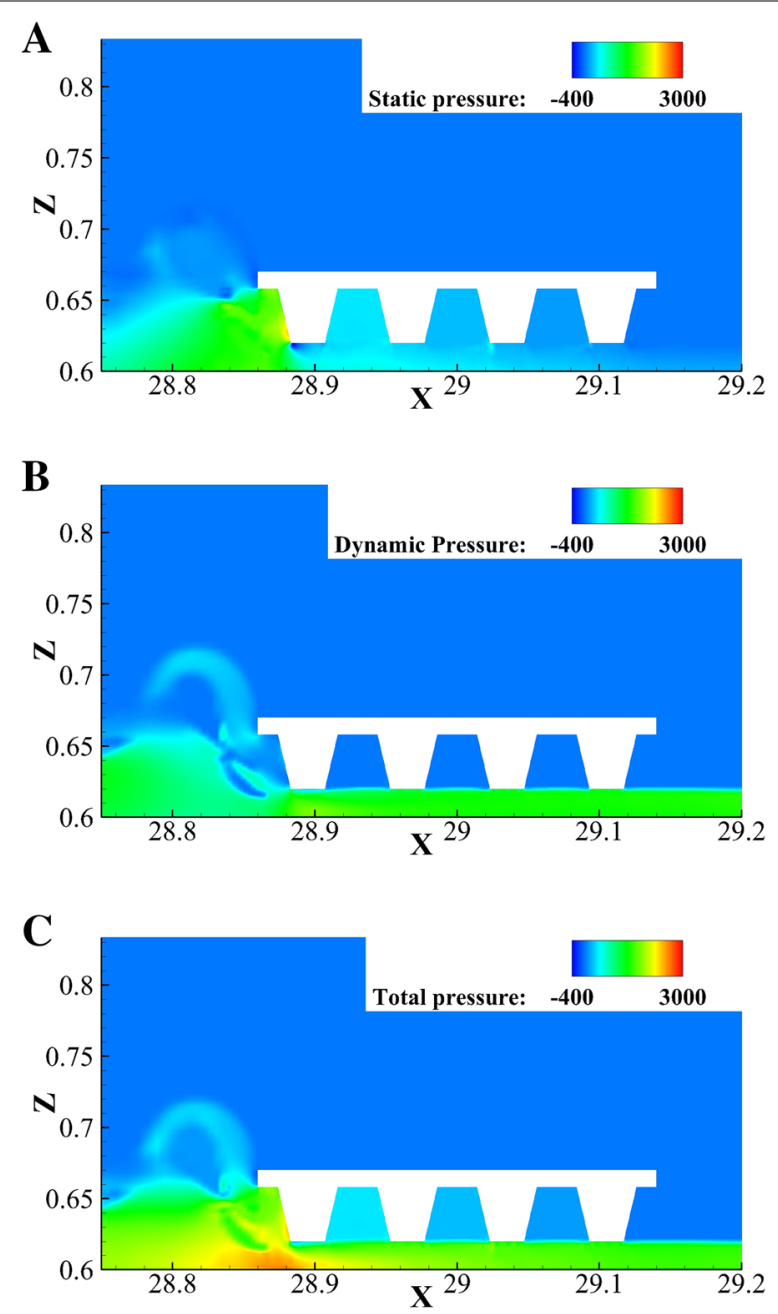

Fig. 18 Static pressure (a), dynamic pressure (b) and total pressure (c) at $t=13.75 \mathrm{~s}$ (units of axes: $\mathrm{m}$, unit of pressure: $\mathrm{Pa}$ )

\section{Influence of clearance on tsunami bore force}

In this section, the water depth and solitary wave height remain unchanged, i.e. $h=$ $0.6 \mathrm{~m}$ and $a=0.21 \mathrm{~cm}$, and the clearance $Z$ changes from $1 \mathrm{~cm}$ to $5 \mathrm{~cm}$ with increment $1 \mathrm{~cm}$. The characteristics of the tsunami force time histories in these cases are similar as those in Fig. 10, therefore the tsunami force time histories are omitted here intentionally. Comparison of horizontal peak values of different clearance is shown in Fig. 24 (a) and comparison of vertical peak values of different clearance is shown in Fig. 24 (b). It can be observed that both $F_{x-\text { max }}^{i m p(f)}$ and $F_{x-\text { max }}^{i m p(s)}$ decrease with clearance. With increase of clearance, not only the time when tsunami bore impacts on box-girder delays, but also the bulk of water volume impacting on box-girder reduces. In other words, the impacting energy on the box-girder reduces. In Fig. 24 (b), both the absolute values of $F_{z-\text { max }}^{i m p(+)}$ and $F_{z-\text { max }}^{i m p(-)}$ generally decreases with clearance. The main reason is that when the clearance is very small, i.e. $Z=1 \mathrm{~cm}$, the tsunami bore impact the panels S13 and S2 more intensively, inducing larger positive vertical peak force; and the bulk of overturning water volume is larger and the impacting on bridge deck panel S11 is more vigorous, 


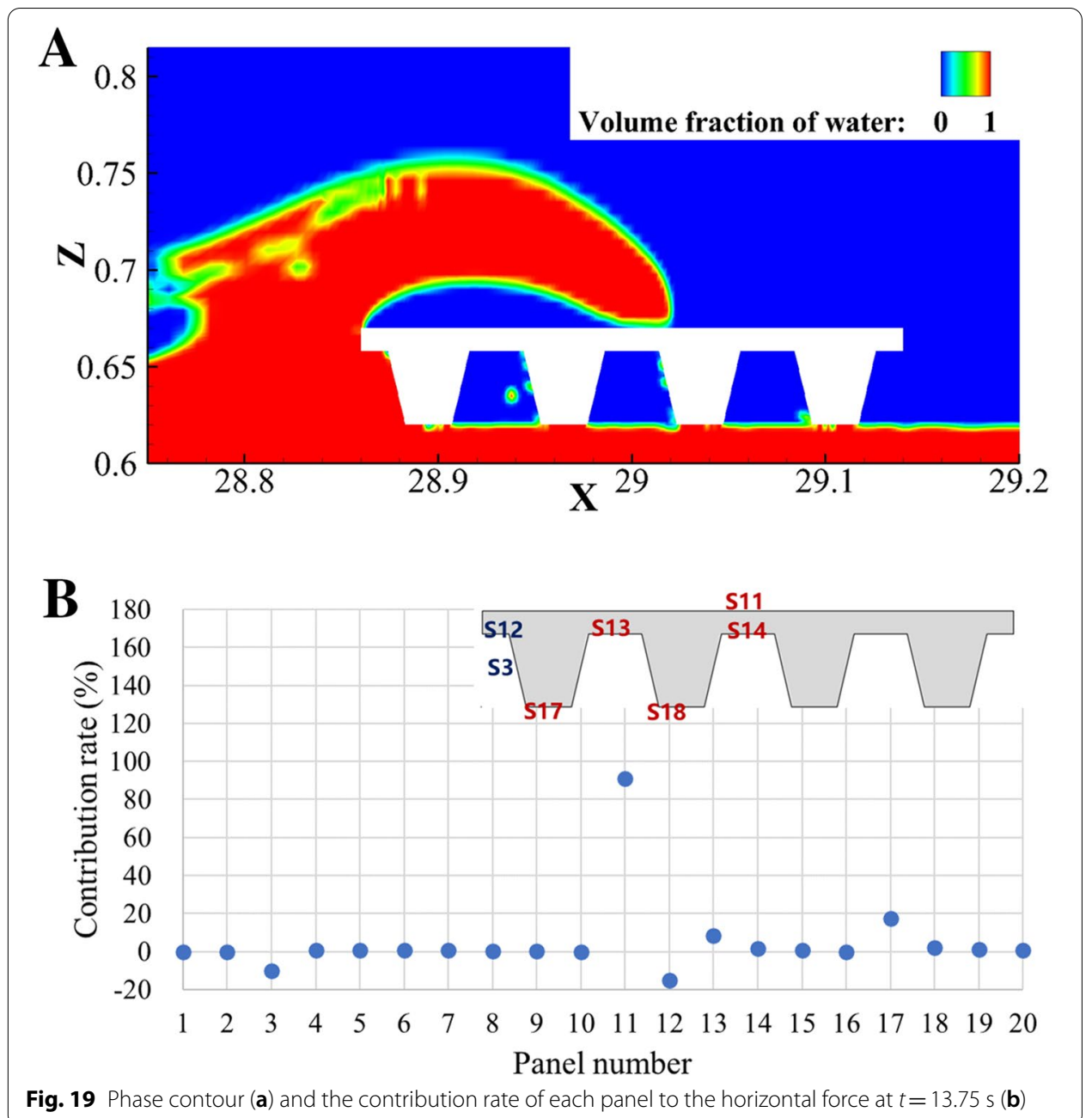

inducing larger negative vertical peak force. However, when the clearance increases to some degree, i.e. $Z=4 \mathrm{~cm}$, both $F_{z-\max }^{i m p}$ and $F_{z-\max }^{i m p(-)}$ approach to zero. Because the panels S13 and S2 are mainly impacted by the lower part of the bore, which has smaller velocity. And the large part of the tongue can overtop the girder, only small part impacts the girder deck, resulting in the smaller negative force.

\section{Conclusions}

This study focus on investigating characteristics and generation mechanism of breaking solitary wave force on box-girder numerically. Firstly the numerical wave flume with a 1:20 slope was built to generate breaking solitary wave. Validation shows that the numerical wave flume not only predicts wave deformation and wave breaking correctly, but also calculates wave force precisely. The main conclusions are:

(1) The time history of horizontal force could be divided into three stages: bottom flow stage, initial impinging stage and second impinging stage. Accordingly, the time his- 

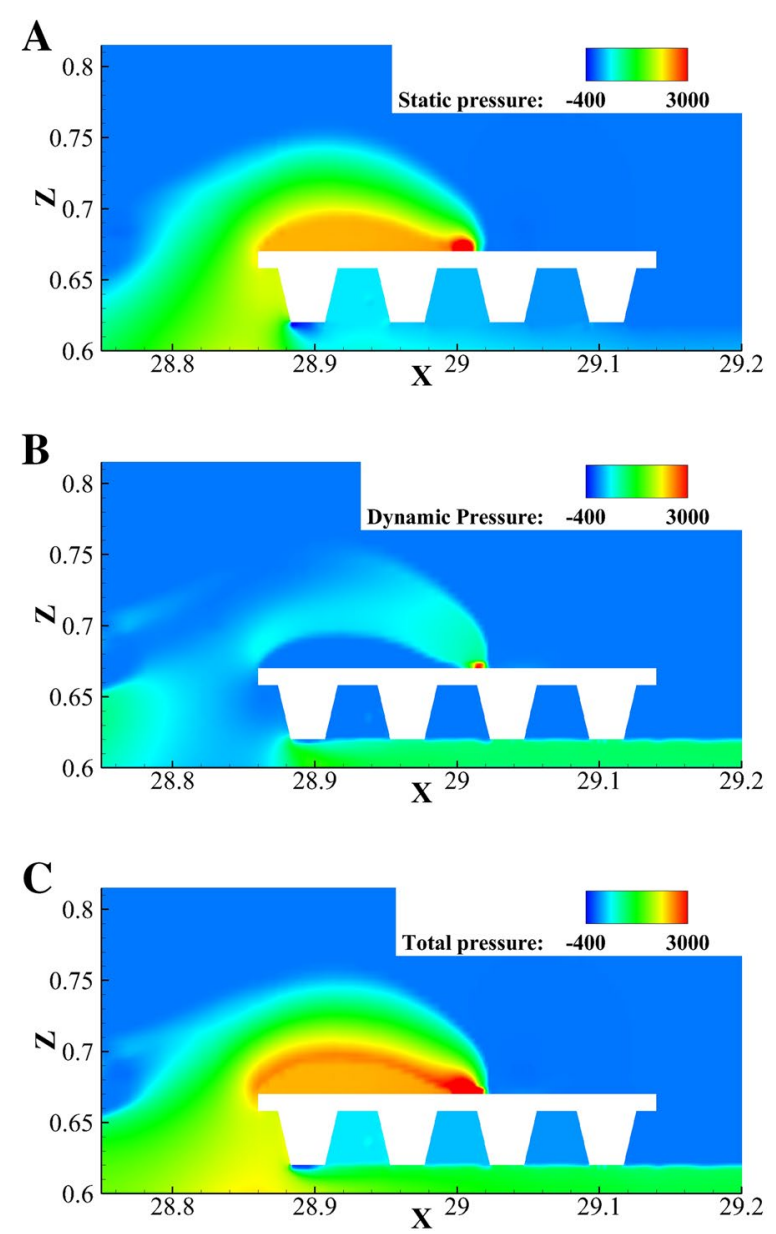

Fig. 20 Static pressure (a), dynamic pressure $(\mathbf{b})$ and total pressure $(\mathbf{c})$ at $t=14.508 \mathrm{~s}$ (units of axes: $\mathrm{m}$, unit of pressure: $\mathrm{Pa}$ )

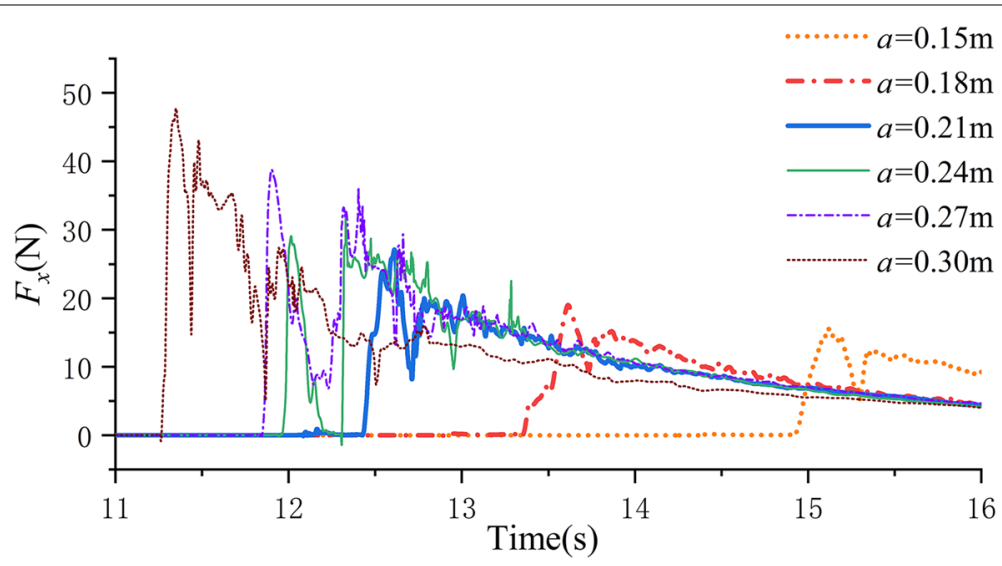

Fig. 21 Comparison of time histories of horizontal forces of the cases with different wave height 


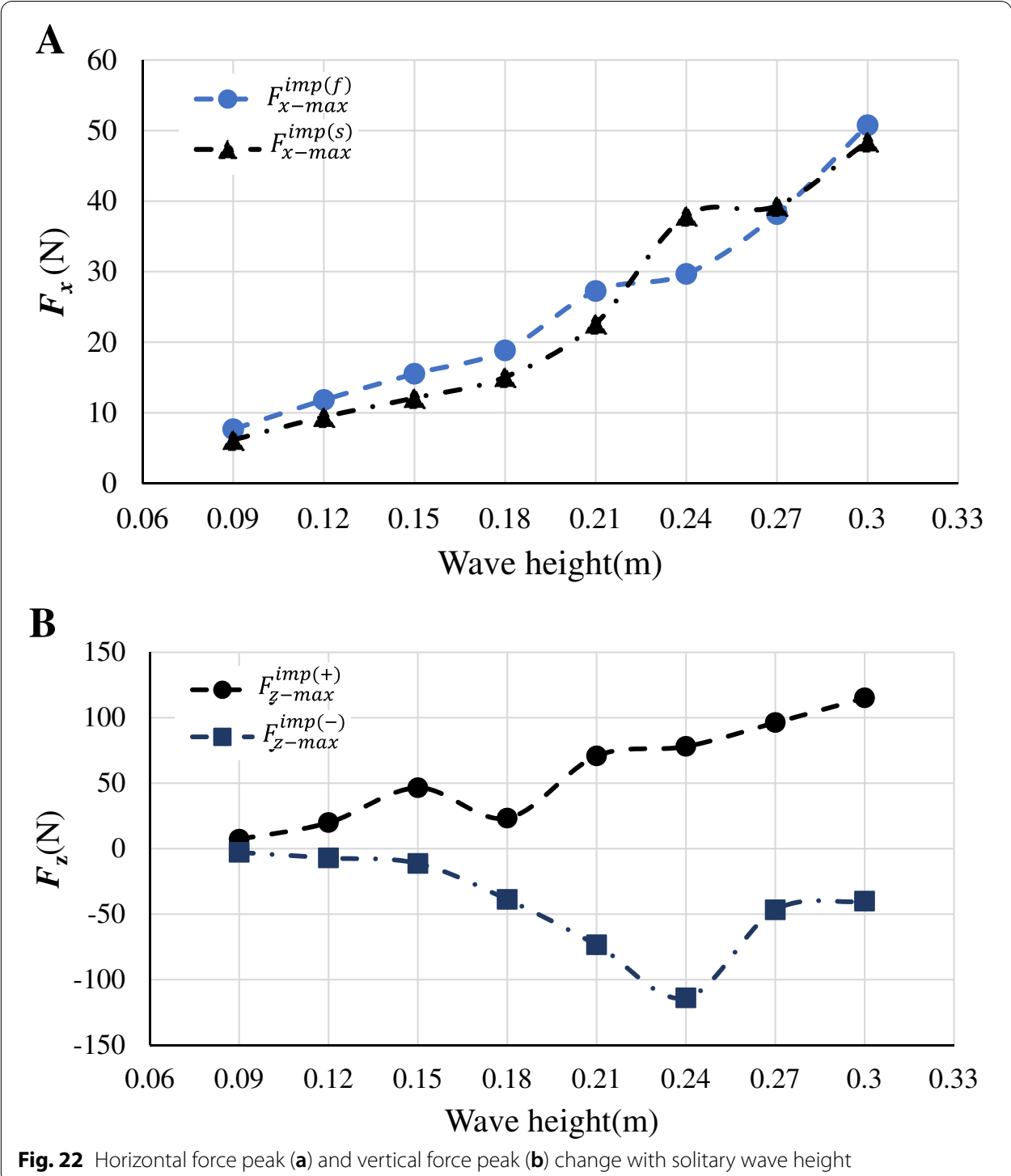

Fig. 22 Horizontal force peak (a) and vertical force peak (b) change with solitary wave height

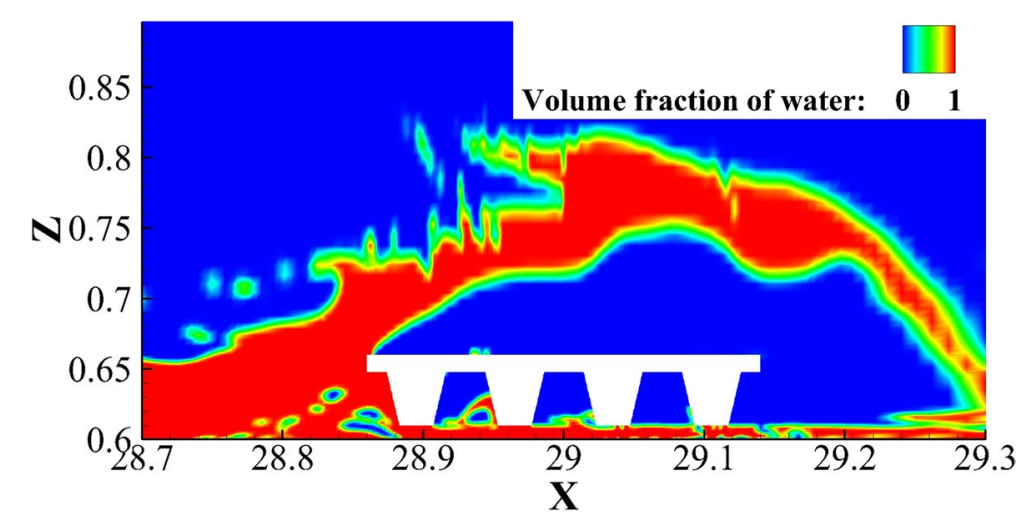

Fig. 23 Phase contour at $t=12.83 \mathrm{~s}$ when water tongue partly strides over the bridge deck, $a=0.27 \mathrm{~m}$ (units of axes: $m$ ) 


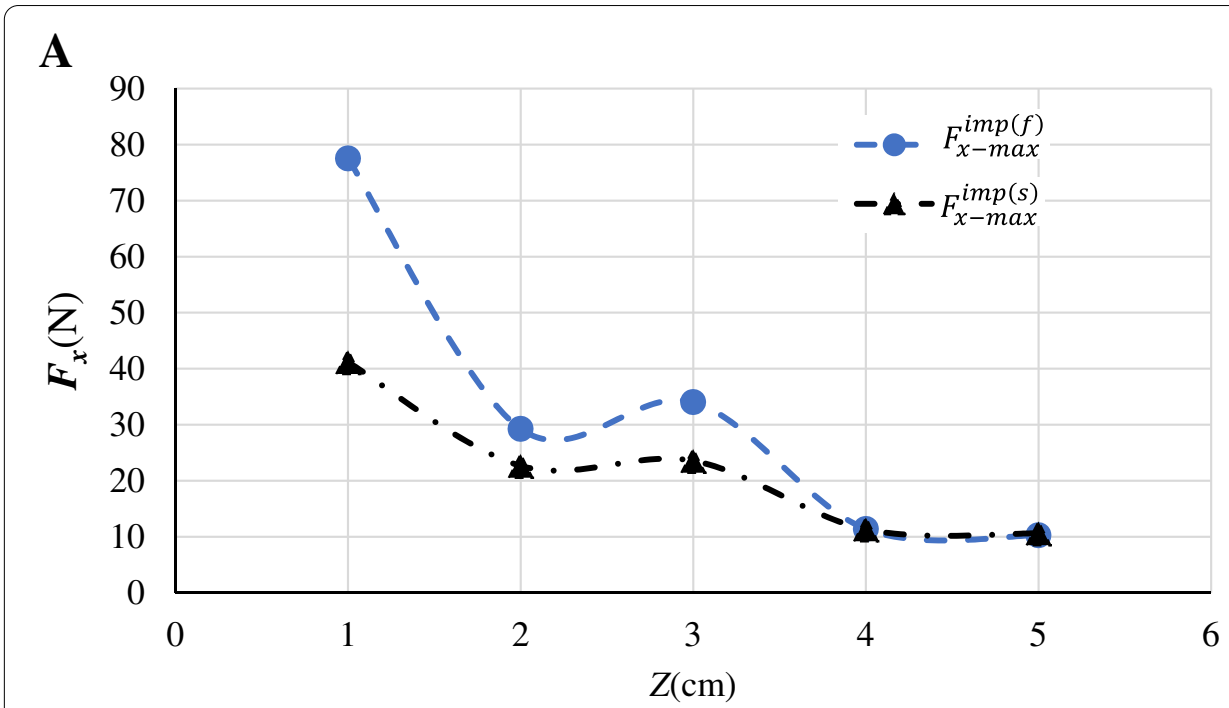

B

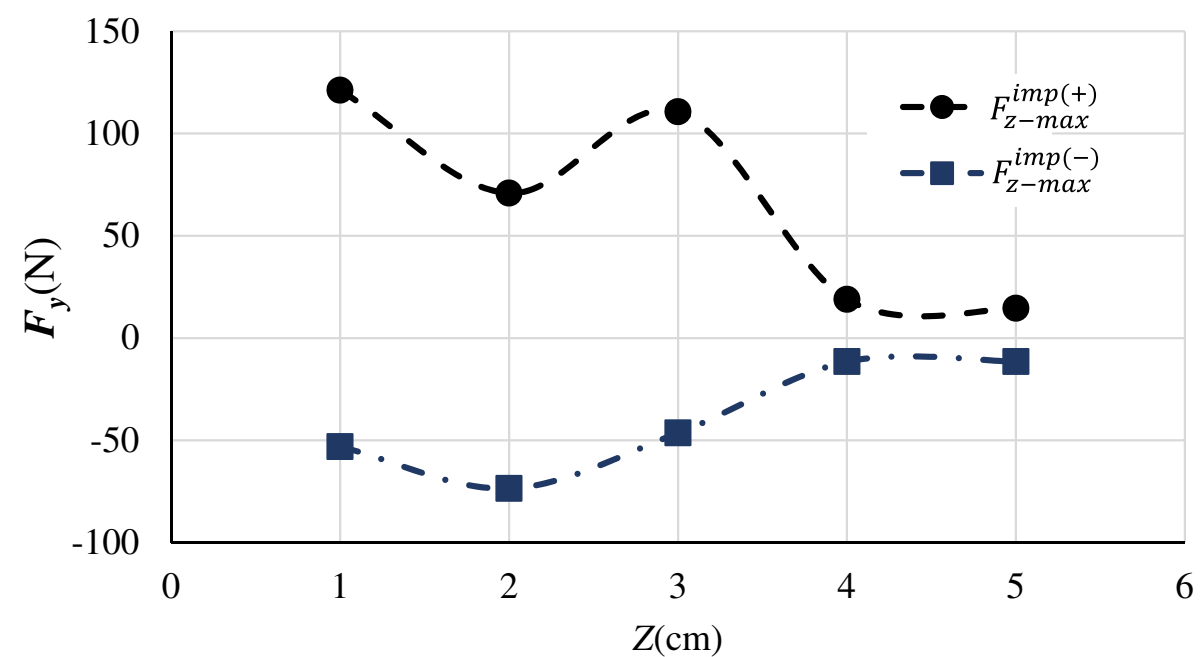

Fig. 24 Changes of horizontal force peak values (a) and vertical force peak values (b) with clearance $Z$

tory of vertical force could be divided into four stages: bottom flow stage, chamber being closed stage, initial impinging stage and second impinging stage.

(2) Peak values of horizontal force are mainly contributed by static pressure on the upstream panels. Positive peak of vertical force is mainly contributed by static pressure on upstream panels S3 and S12 resulted from impinging, as well as the static pressure on the panels in chambers by pressed air. Negative peak of vertical force is dominated by static pressure on girder deck (the panel S11) resulted from water tongue impacting and pressing of entrapped air.

(3) Peak values of horizontal force and positive peak value of vertical force increase with solitary wave height $a$, and negative peak value of vertical force increases with $a$ when $a \leq 0.24 \mathrm{~m}$, but it is decreases with $a$ when $a>0.24 \mathrm{~m}$. Absolute values of peak values of both horizontal and vertical forces decrease with clearance. 
However, the influence of water depth, slope gradient, the distance between the slope top and girder, etc. on breaking solitary wave force on box-girder still requires further investigation.

\section{Abbreviations}

CFD: Computational Fluid Dynamics; RANS: Reynolds-averaged Navier-Stokes; UDF: User Defined Function; VOF: Volume of Fluid.

\section{Acknowledgements}

The authors thanks the supports from the National Natural Science Foundation of China, Science and Technology Planning Project of Sichuan Province.

\section{Authors' contributions}

Wanli Yang: Conceptualization, Methodology, Data analysis, Writing - Original draft and review. Sijing Li: Modeling, Investigation, Computing, Data analysis. Junling Liu: Validation, Data analysis. Wenbo Wu: Investigation, Writing - text editing. Hui Li: Figure drawing. Ning Wang: Methodology, Funding secure, Supervision. The author(s) read and approved the final manuscript.

\section{Funding}

National Natural Science Foundation of China (Grant no. 51678491), Science and Technology Planning Project of Sichuan Province (Grant No. 2021JDTD0012).

\section{Availability of data and materials}

No objection for data sharing.

Declaration

\section{Competing interests}

No competing interests.

\section{Author details}

${ }^{1}$ Department of Bridge Engineering, School of Civil Engineering, Southwest Jiaotong University, Chengdu 610031, China.

${ }^{2}$ Aseismic Engineering Technology Key Laboratory of Sichuan Province, Chengdu 610031, China. ${ }^{3}$ Department of Structural Engineering, School of Civil Engineering, Southwest Jiaotong University, Chengdu 610031, China. ${ }^{4}$ School of Civil Engineering, Southwest Jiaotong University, Chengdu 610031, China.

Received: 19 June 2021 Accepted: 6 September 2021

Published online: 13 December 2021

\section{References}

Chen H, Ma Y, Ma X, Dong G (2017) Laboratory study on geometric characteristics of limiting waves in shallow water. Acta Oceanol Sin 39(2):105-111

Cross RH (1967) Tsunami surge forces. J Waterways Harbors Div 93(4):201-234

Feng Y (2005) The great tsunami in history-the Chilean tsunami in 1960. Disaster Reduction China 000(003):56-57

Goring DG, Raichlen F (1980) The generation of long waves in the laboratory. Coast Eng 1980:763-783

Goring DG, Raichlen F (1992) Propagation of long waves onto shelf. J Waterway Port Coastal Ocean Eng 118(1):43-61

Grilli ST (1997) Breaking criterion and characteristics for solitary waves on slopes. J Waterway, Port, Coastal Ocean Eng 123:102-112

Hayatdavoodi M, Seiffert B, Ertekin RC (2014) Experiments and computations of solitary-wave forces on a coastal-bridge deck. Part II: deck with girders. Coast Eng 88(88):210-228

Hsiao SC, Hsu TW, Lin TC et al (2008) On the evolution and run-up of breaking solitary waves on a mild sloping beach. Coast Eng 55(12):975-988

Huang B, Ren QY, Cui XL, Zhang JW, Zhu B (2020) Study of wave forces acting on the box-girder superstructure of coastal bridges in the submerged condition based on potential flow theory. Adv Bridge Eng

Huang B, Yang Z, Zhu B, Chang YH (2019) Vulnerability assessment of coastal bridge superstructure with box girder under solitary wave forces through experimental study. Ocean Eng 189(Oct.1):106337.1-106337.14

lemura H, Pradono MH, Yasuda T, Tada T (2007) Experiments of tsunami force acting on bridge models. J JSCE 29(0):902-911

Kasano H, Oka J, Sakurai J, Yoda T (2012) Investigative research on bridges subjected to tsunami disaster in 2011 off the pacific coast of tohoku earthquake. In: Australasian structural engineering conference 2012: the past, present and future of structural engineering

Kosa K, Sasaki T, Fu L (2014) Tsunami force on bridge comparison of two wave types by experimental test. Kozo Kogaku Ronbunshu a 60:282-292

Lau TL, Lukkunaprasit P, Inoue S, Ohmachi T (2011) Experimental and numerical modeling of tsunami force on bridge decks. INTECH Open Access Publisher, Vienna

Park H, Do T, Tomiczek TT, Cox D, John W (2018) Numerical modeling of non-breaking, impulsive breaking, and broken wave interaction with elevated coastal structures: laboratory validation and inter-model comparisons. Ocean Eng 158(JUN.15):78-98 
Ramsden JD, Raichlen F (1990) Forces on vertical wall caused by incident bores. J Waterway Port Coastal Ocean Eng 116(5):592-613

Salem H, Mohssen S, Kosa K, Hosoda A (2014) Collapse analysis of Utatsu Ohashi bridge damaged by Tohuku tsunami using applied element method. J Adv Concr Technol 12(10):388-402

Seiffert B, Hayatdavoodi M, Ertekin RC (2014) Experiments and computations of solitary-wave forces on a coastal-bridge deck. Part I: flat plate. Coastal Eng 88:194-209

Sugimoto T, Unjoh S (2007) Hydraulic model tests on the bridge structures damaged by tsunami and tidal wave. In: Proceedings of the 23th US-Japan bridge engineering workshop, Tsukuba, Japan, vol 57, p 110

Unjoh S, Endoh K (2006) Damage investigation and the preliminary analyses of bridge damage caused by the 2004 Indian Ocean tsunami. In: Proceedings of the 38th UJNR joint panel meeting

Wu L (2017) Study on the tsunami force of the superstructures of the medium and small span bridges. (MA.Eng Dissertation) Southwest Jiaotong University, P.R. China (in Chinese)

Xu G, Cai C, Cai CS, Hu P, Dong Z (2016) Component level-based assessment of the solitary wave forces on a typical coastal bridge deck and the countermeasure of air venting holes. Pract Period Struct Des Constr 21(4):04016012

Yang WL, Lai WJ, Zhu QL, Zhang CJ, Li FH (2020) Study on generation mechanism of vertical force peak values on T-girder attacked by tsunami bore. Ocean Eng 196(Jan.15):106782.1-106782.16

Zhu D, Dong Y (2020) Experimental and 3D numerical investigation of solitary wave forces on coastal bridges. Ocean Eng 209:107499

Zhu H, Yu Y, Dai S (2006) The research progress in numerical simulation of tsunami models. J Hydrodyn 21(6)

\section{Publisher's Note}

Springer Nature remains neutral with regard to jurisdictional claims in published maps and institutional affiliations.

\section{Submit your manuscript to a SpringerOpen ${ }^{\circ}$ journal and benefit from:}

- Convenient online submission

Rigorous peer review

- Open access: articles freely available online

- High visibility within the field

Retaining the copyright to your article

Submit your next manuscript at $\boldsymbol{\Delta}$ springeropen.com 